Review

\title{
Genetic Alterations in Childhood Acute Lymphoblastic Leukemia: Interactions with Clinical Features and Treatment Response
}

\author{
Shawn H. R. Lee ${ }^{1,2}$, Zhenhua Li ${ }^{2}$, Si Ting Tai ${ }^{2}$, Bernice L. Z. Oh ${ }^{1,2}$ and Allen E. J. Yeoh ${ }^{1,2, *}$ \\ 1 VIVA-University Children's Cancer Centre, Khoo-Teck Puat-National University Children's Medical Institute, \\ National University Hospital, Singapore 119074, Singapore; paelhrs@nus.edu.sg (S.H.R.L.); \\ paeolzb@nus.edu.sg (B.L.Z.O.) \\ 2 Department of Pediatrics, Yong Loo Lin School of Medicine, National University of Singapore, \\ Singapore 119074, Singapore; paeliz@nus.edu.sg (Z.L.); t.siting@nus.edu.sg (S.T.T.) \\ * Correspondence: allen.yeoh@nus.edu.sg
}

Citation: Lee, S.H.R.; Li, Z.; Tai, S.T.; Oh, B.L.Z.; Yeoh, A.E.J. Genetic Alterations in Childhood Acute Lymphoblastic Leukemia: Interactions with Clinical Features and Treatment Response. Cancers 2021, 13, 4068. https://doi.org/ $10.3390 /$ cancers 13164068

Academic Editor: Ilaria Iacobucc

Received: 8 July 2021

Accepted: 8 August 2021

Published: 12 August 2021

Publisher's Note: MDPI stays neutral with regard to jurisdictional claims in published maps and institutional affiliations.

Copyright: (c) 2021 by the authors. Licensee MDPI, Basel, Switzerland. This article is an open access article distributed under the terms and conditions of the Creative Commons Attribution (CC BY) license (https:// creativecommons.org/licenses/by/ $4.0 /)$.
Simple Summary: The latest molecular taxonomy of acute lymphoblastic leukemia (ALL) comprises $>20$ distinct genetic subtypes, each with their own unique clinical and prognostic characteristics. In this review, we describe how these new genetic subtypes interact with clinical presenting features, $I K Z F 1^{\text {del }}$, treatment response, and outcomes, which is helpful for clinical use.

Abstract: Acute lymphoblastic leukemia (ALL) is the most common cancer among children. This aggressive cancer comprises multiple molecular subtypes, each harboring a distinct constellation of somatic, and to a lesser extent, inherited genetic alterations. With recent advances in genomic analyses such as next-generation sequencing techniques, we can now clearly identify $>20$ different genetic subtypes in ALL. Clinically, identifying these genetic subtypes will better refine risk stratification and determine the optimal intensity of therapy for each patient. Underpinning each genetic subtype are unique clinical and therapeutic characteristics, such as age and presenting white blood cell (WBC) count. More importantly, within each genetic subtype, there is much less variability in treatment response and survival outcomes compared with current risk factors such as National Cancer Institute (NCI) criteria. We review how this new taxonomy of genetic subtypes in childhood ALL interacts with clinical risk factors used widely, i.e., age, presenting $\mathrm{WBC}, I K Z F 1^{\text {del }}$, treatment response, and outcomes.

Keywords: childhood acute lymphoblastic leukemia; genetic subtypes; RNA-Seq; NCI criteria; MRD; IKZF1 ${ }^{\text {del }}$

\section{Introduction}

The most common type of cancer in children is acute lymphoblastic leukemia (ALL). Despite being one of the most curable cancers, with 5-year overall survival (OS) exceeding $90 \%$ with contemporary protocols [1], ALL remains a leading cause of cancer-related death in children and young adults [2].

Based on its lineage of origin, ALL can be broadly divided into B-lymphoblastic (B-ALL) and T-lymphoblastic leukemia (T-ALL), each harboring distinct constellations of somatic genetic alterations [3,4]. Advances in genomic analyses have enabled comprehensive interrogations of these genetic alterations, which in turn have improved the molecular taxonomy of ALL [5]. This deeper understanding of the molecular taxonomy of ALL has allowed us to further refine the current risk assignment beyond the conventional National Cancer Institute (NCI) criteria of age and white blood cell (WBC) count, and minimal residual disease (MRD). In this review, we focus on how NCI criteria, MRD, and IKZF1 $1^{\text {del }}$ interact with the new improved molecular taxonomy of ALL subtypes (Figure 1). 


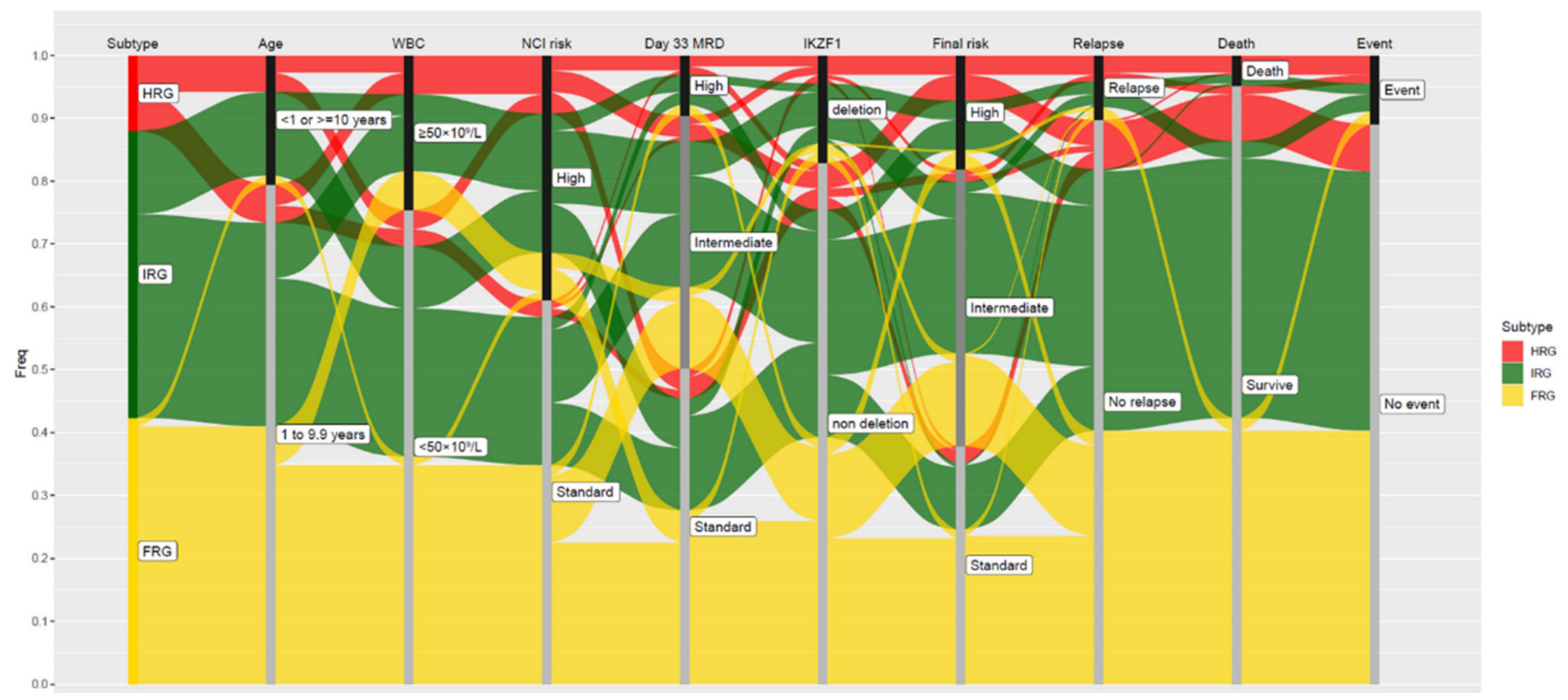

Figure 1. Interactions of genetic risk groups with various clinical prognostic risk factors and outcomes in childhood acute lymphoblastic leukemia (ALL). Each vertical stack in this Sankey diagram represents a prognostic factor or treatment outcome, with subcategories in different shades of black and gray. The relationships between various prognostic factors are demonstrated by flow lines, and the widths of the flow lines are proportional to the degree of interaction between genetics and clinical factors/outcomes. Favorable-risk subtypes are in shades of yellow, intermediate-risk subtypes are in shades of green, and high-risk subtypes are in shades of red. Day 33 MRD is categorized into three groups: standard, $\leq 0.01 \%$; intermediate, $0.01 \%$ to $1 \%$; high, $\geq 1 \%$. Data are adapted from results of RNA-sequencing of children and adolescents with ALL in the Malaysia-Singapore cohort. Abbreviations: WBC, white blood cell; NCI: National Cancer Institute; MRD: minimal residual disease; HRG, high-risk genetics; IRG: intermediate-risk genetics; FRG: favorable-risk genetics.

\section{ALL Genetic Subtypes in $\mathbf{2 0 2 0}$ and Beyond}

Next-generation sequencing (NGS) technologies such as RNA-Seq, whole genome/ whole exome sequencing (WGS/WES), and multiplex ligation probe-dependent amplification (MLPA) are increasingly used to define genetic subtypes. Using RNA-Seq, investigators from the Malaysia-Singapore (Ma-Spore) ALL study group could define $>20$ genetic subtypes of ALL, each with its own distinct genetic driver (Table 1).

Individually, these 20 genetic subtypes have their own distinct clinical characteristics, patterns of MRD response, and treatment outcomes. Based on their reported 5-year cumulative risk of relapse (CIR) and recommended treatment intensity, in this review we grouped them into three genetic risk groups: favorable- (FRG), intermediate- (IRG), and high-risk genetics (HRG) (Figure 1).

\subsection{Favorable-Risk Genetics (FRG) Group}

The favorable-risk genetics (FRG) group is defined as subtypes with $<10 \% 5$-year CIR (Table 1) and where de-intensification of therapy is safe and possible. This FRG group comprises two major classical subtypes: (1) ETV6-RUNX1 and (2) Hyperdiploid >50 chromosomes. These two subtypes can usually be defined by conventional cytogenetics and RT-PCR. In addition, using the gene expression level of every gene on each chromosome, RNA-Seq can perform digital karyotyping by identifying the ploidy status of each chromosome. FRG accounted for $\sim 40 \%$ of both the Ma-Spore and St Jude Total 15 cohorts (Figure 2). 
Table 1. Overview of B-ALL subtypes and summary of clinical characteristics of individual subtypes based on Malaysia-Singapore 2003 and 2010 trials.

\begin{tabular}{|c|c|c|c|c|c|c|c|c|c|c|}
\hline $\begin{array}{l}\text { Risk } \\
\text { Group }\end{array}$ & Subtype & $\begin{array}{l}\text { Proportion } \\
\text { of B-ALL }\end{array}$ & $\begin{array}{c}\text { Median Age at } \\
\text { Presentation, } \\
\text { Years (Range) }\end{array}$ & $\begin{array}{c}\text { Median } \\
\text { Presenting } \\
\text { WBC, } \times 10^{9} / \mathrm{L} \\
\text { (Range) }\end{array}$ & $\begin{array}{c}\text { Proportion of } \\
\text { MRD-Negative } \\
\text { at EOI, \% (No } \\
\text { of Patients) }\end{array}$ & $\begin{array}{c}\text { Proportion of } \\
\text { MRD-Negative } \\
\text { at EOC, \% (No } \\
\text { of Patients) }\end{array}$ & 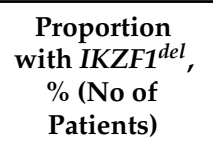 & $\begin{array}{l}\text { Interaction with } \\
\text { IKZF } 1^{\text {del }}\end{array}$ & $\begin{array}{l}\text { 5-y CIR, \% } \\
\text { (Range) }\end{array}$ & $\begin{array}{l}\text { 5-y OS, \% } \\
\text { (Range) }\end{array}$ \\
\hline \multirow{2}{*}{ FRG } & ETV6-RUNX1 & $20 \%$ & $4.0(1.6-14)$ & $12(1-285)$ & $76 \%(52 / 86)$ & $98 \%(60 / 61)$ & $7 \%(5 / 70)$ & Possible attenuating & $5.2(1.3$ to 13$)$ & $100 \%$ \\
\hline & Hyperdiploidy & $24 \%$ & $3.7(1.4-12.2)$ & $9(1-608)$ & $54 \%(46 / 85)$ & $92 \%(58 / 63)$ & $6 \%(4 / 66)$ & Possible attenuating & $5.5 \%$ (1.7 to 12.6$)$ & $98.8 \%(91.8$ to 99.8$)$ \\
\hline \multirow{9}{*}{ IRG } & TCF3-PBX1 & $5 \%$ & $4.8(1.5-15.6)$ & $56(6-224)$ & $58 \%(11 / 19)$ & $94 \%(17 / 18)$ & $0 \%(0 / 18)$ & Possible attenuating & $5.6 \%(0.3$ to 23.1$)$ & $94.4 \%$ (66.6 to 99.2$)$ \\
\hline & DUX4 & $14 \%$ & $9.8(2.4-16.7)$ & $10(2-142)$ & $22 \%(11 / 50)$ & $82 \%(33 / 40)$ & $28 \%(13 / 46)$ & Possible attenuating & $8.9 \%$ (2.8 to 19.5$)$ & $97.8 \%(85.3$ to 99.7$)$ \\
\hline & ETV6-RUNX1-like & $2 \%$ & $2.7(1.4-12.6)$ & $69(1-278)$ & $57 \%(4 / 7)$ & $83 \%(5 / 6)$ & $62 \%(5 / 8)$ & None & $12.7 \%(0.5$ to 45.3$)$ & $88.9 \%$ (43.3 to 98.4$)$ \\
\hline & ZNF384 & $5 \%$ & $6.8(2.1-15.7)$ & $37(5-140)$ & $18 \%(3 / 17)$ & $77 \%(10 / 13)$ & $19 \%(3 / 16)$ & None & $6.3 \%(0.4$ to 25.5$)$ & $93.3 \%(61.3$ to 99.0$)$ \\
\hline & ZNF384-like & $1 \%$ & $5.1(2.5-7.7)$ & $76(62-90)$ & $50 \%(1 / 2)$ & $50 \%(1 / 2)$ & $0 \%(0 / 1)$ & None & - & - \\
\hline & NUTM1 & $1 \%$ & $2.4(0.8-11.3)$ & $33(11-53)$ & $100 \%(3 / 3)$ & $100 \%(1 / 1)$ & $0 \%(0 / 3)$ & None & $0.0 \%$ & $100.0 \%$ \\
\hline & PAX5alt & $10 \%$ & $3.9(0.7-17.4)$ & $24(2-509)$ & $39 \%(12 / 31)$ & $89 \%(25 / 28)$ & $28 \%(9 / 32)$ & $\begin{array}{l}\text { Poorer prognosis, } \\
\text { IKZF }\end{array}$ & $18.1 \%$ (6.3 to 34.7$)$ & $92.8 \%$ (73.7 to 98.2$)$ \\
\hline & PAX5-P80R & $1 \%$ & $5.7(5.0-6.3)$ & $3(2-5)$ & $0 \%(0 / 2)$ & $100 \%(1 / 1)$ & $0 \%(0 / 2)$ & $\begin{array}{l}\text { Poorer prognosis, } \\
\text { IKZF }\end{array}$ & - & - \\
\hline & B-Others & $7 \%$ & $5.1(0.6-13.0)$ & $8(1-124)$ & $45 \%(10 / 22)$ & $89 \%(16 / 18)$ & $0 \%(0 / 21)$ & None & $20.7 \%$ (7.3 to 39.0$)$ & $94.1 \%(65.0$ to 99.1$)$ \\
\hline \multirow{8}{*}{ HRG } & $\mathrm{Ph}(B C R-A B L 1)$ & $2 \%$ & $10.6(2.7-15.2)$ & $180(7-708)$ & $44 \%(4 / 9)$ & $83 \%(5 / 6)$ & $44 \%(4 / 9)$ & Poorer prognosis & $37.5 \%(7.2$ to 69.4$)$ & $75.0 \%$ (31.5 to 93.1$)$ \\
\hline & $\begin{array}{c}\text { Ph-like } \\
\text { (BCR-ABL-like) }\end{array}$ & $2 \%$ & $8.0(2.4-14.1)$ & $22(4-518)$ & $12 \%(1 / 8)$ & $60 \%(3 / 5)$ & $60 \%(3 / 5)$ & Poorer prognosis & $37.5 \%$ (6.9 to 69.8$)$ & $75.0 \%$ (31.5 to 93.1$)$ \\
\hline & $M L L(K M T 2 A)$ & $3 \%$ & $0.5(0.2-3.4)$ & $42(5-247)$ & $11 \%(1 / 9)$ & $43 \%(3 / 7)$ & $0 \%(0 / 10)$ & None & $54.3 \%$ (16.7 to 81.2$)$ & $64.8 \%(25.3$ to 87.2$)$ \\
\hline & Hypodiploidy & $1 \%$ & $15.1(13.8-16.4)$ & $9(6-12)$ & $0 \%(0 / 1)$ & $0 \%(0 / 1)$ & $0 \%(0 / 1)$ & None & $50.0 \%(0.0$ to 96.0$)$ & $50.0 \%$ (0.6 to 91.0$)$ \\
\hline & Near-haploidy & $1 \%$ & $6.6(4.3-8.3)$ & $26(4-246)$ & $100 \%(3 / 3)$ & $100 \%(3 / 3)$ & $0 \%(0 / 2)$ & None & $50.0 \%(0.0$ to 96.0$)$ & $50.0 \%$ (0.6 to 91.0$)$ \\
\hline & $M E F 2 D$ & $1 \%$ & $11.0(4.9-12.4)$ & $7(5-11)$ & $100 \%(4 / 4)$ & $100 \%(3 / 3)$ & $0 \%(0 / 4)$ & None & $0.0 \%$ & $100.0 \%$ \\
\hline & $H L F-r$ & $<1 \%$ & $5.2(5.2-5.2)$ & $183(183-183)$ & $0 \%(0 / 1)$ & N.A & $0 \%(0 / 1)$ & None & - & - \\
\hline & CRLF2 & $3 \%$ & $8.3(3.0-17.3)$ & $59(11-145)$ & $22 \%(2 / 9)$ & $88 \%(7 / 8)$ & $80 \%(8 / 10)$ & Poorer prognosis & $20.0 \%(2.6$ to 49.2$)$ & $59.1 \%(16.0$ to 86.0$)$ \\
\hline
\end{tabular}




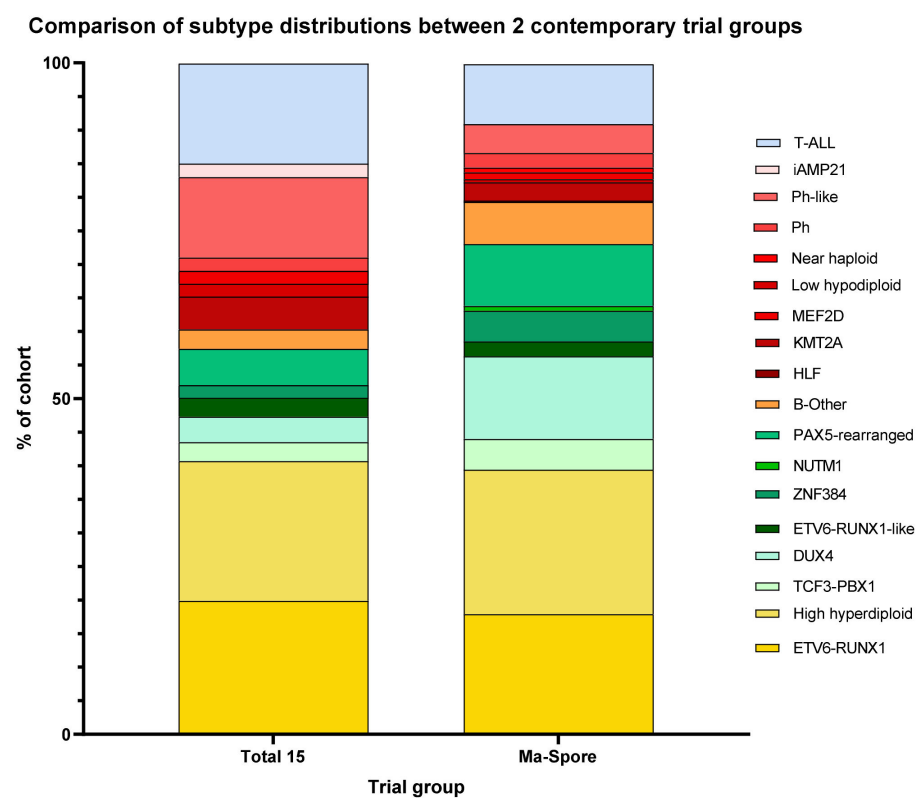

Figure 2. Spectrum of molecular subtypes of childhood ALL in the St Jude Total 15 cohort in the USA and the Malaysia-Singapore (Ma-Spore) cohort in Asia. The bar charts depict the estimated frequencies of each subtype of ALL among patients treated in these two frontline trials, updated with the current taxonomy of novel genetic abnormalities. The distribution profile differs slightly between these two cohorts, which is plausibly race-related, e.g., in proportions of DUX4, Ph-like, or T-ALL. Among the B-ALL subgroup, favorable-risk subtypes are in shades of yellow, intermediate-risk subtypes are in shades of green, and high-risk subtypes are in shades of red; B-Other is noted in orange; T-ALL is represented separately in blue. Data from Total 15 are reproduced with permission from Pui et al. Nat Rev Clin Oncol 2019. The prognosis of genetic subtypes possibly varies slightly between trial groups due to differences in risk stratification and treatment intensity, e.g., currently DUX4 is now regarded by some trials (such as the recent St Jude Total 16 trial) as favorable-risk.

For FRG in the Ma-Spore cohort, $60 \%$ of patients were NCI standard risk (SR). Of the patients in FRG, 45\% achieved end-of-induction (EOI)-MRD negativity, while 37\% were EOI-MRD IR (i.e., EOI MRD $\geq 0.01 \%$ and $<1 \%$ ) and $12 \%$ EOI-MRD HR (i.e., EOI MRD $\geq 1 \%$ ). In FRG, only EOI-MRD HR and Ma-Spore HR criteria conferred a poorer event-free survival (EFS). Otherwise, all other criteria including NCI criteria, EOI-MRD SR and IR response, and treatment on Ma-Spore SR and IR arms did not significantly affect FRG survival. FRG had excellent 5-year CIR, EFS, and OS rates of 5\%, $94 \%$, and $100 \%$, respectively. Furthermore, relapses in FRG are usually highly salvageable.

In the Children's Oncology Group (COG), NCI SR with FRG are called SR-low risk. In this COG SR-low risk group, intensification through additional doses of PEG-asparaginase did not improve outcome [6]. In the Ma-Spore ALL 2010 (MS2010) trial, FRG who were also EOI-MRD-negative had exceedingly good outcomes using an anthracycline-free chemotherapy protocol. Similar to Ma-Spore, the UKALL2003 reported that only FRG with high EOI MRD $\geq 0.1 \%$ had poorer 5-year CIR $>10 \%$ [7]. Therefore, in the ongoing prospective MS2020 study, FRG will receive de-intensified therapy even with a low positive EOI MRD $(<0.1 \%)$. FRG will receive a more intensified therapy only if EOI MRD $(\geq 0.1 \%)$, or if subsequent MRD timepoints are positive.

Although TCF3-PBX1 and DUX4 have low 5-year CIR $(<10 \%)$, most trial groups (including us in the Ma-Spore trial group) kept them stratified as intermediate-risk genetics (IRG). Traditionally, TCF3-PBX1 had poor treatment outcomes with less intensive therapy (see below). Because of these previously poor results, de-intensification of therapy for $T C F 3-P B X 1$ carries significant risk. As such, despite a low CIR of $<10 \%$, we continue to regard TCF3-PBX1 as IRG. DUX4 patients also continue to be regarded as IRG, because they tended to have high PCR-based EOI MRD. For this reason, the majority of DUX4 patients 
were treated in IR and HR groups in the MS2003 [8] or MS2010 [9] studies, and even had hematopoietic stem cell transplant (HSCT) in first complete remission (CR) (see below).

\subsection{Intermediate-Risk Genetics (IRG) Group}

IRG, which accounts for $\sim 45 \%$ of B-ALL, is the most genetically diverse group, comprising $>10$ different genetic subtypes (Table 1). Most IRG subtypes have an intermediate 5-year CIR of 10-20\%. There are three exceptions with good outcomes: (1) TCF3-PBX1, (2) DUX4, and (3) ZNF384-rearranged (ZNF384-r). The remaining IRG are separately grouped based on similarity in gene expression profiles (GEP) or other rare genomic alterations. Despite their similar GEP, members of each group can be molecularly diverse and can have various distinct fusion partners. Individual fusion partners are rare by themselves, although most have been reported recurrently. Because of this rarity, we are unable to do further risk assignment based on the fusion partner. Within IRG, DUX4 forms the largest genetic subgroup, with PAX5alt as the second largest group.

In Ma-Spore trials, almost 50\% of IRG had an intermediate MRD response: $50 \%$ were MRD-positive at EOI but became MRD-negative by end-of-consolidation (EOC). The 5-year CIR ranged from $12.7 \%$ in ETV6-RUNX1-like to $20.7 \%$ in the B-others group (Table 1).

T-ALL lacks genetic prognostically distinct groups and has an intermediate 5-year CIR. The outcome of T-ALL has improved significantly with contemporary ALL therapy. In COG AALL0434 and MS2003, T-ALL outcomes have now approached that of B-ALL [10].

\subsection{High-Risk Genetics (HRG) Group}

The high-risk genetics (HRG) group is also genetically heterogeneous. This group accounts for around $15 \%$ of B-ALL, amongst which KMT2A rearrangements (KMT2A-r) and $B C R-A B L 1$ each account for $\sim 3 \%$. RNA-Seq has transformed the classification of the "B-others" category by conventional genetics. Specifically, using RNA-Seq, we can now define 13 distinct genetic subtypes in this conventional B-others group (Table 1). Of these 13 RNA-Seq genetic subtypes, five are especially high-risk: (1) $B C R-A B L 1$, (2) KMT2A-r, (3) MEF2D, (4) HLF-r, and (5) CRLF2/BCR-ABL1-like ALL. These HRG are more prevalent in the USA, accounting for $12 \%$ of cases in the Total 15 cohort. In contrast, they occur in only $4 \%$ of the Ma-Spore patients (Figure 2). In MS2003/2010, patients in the HRG group have a high (20-55\%) 5-year CIR.

\section{Association of Subtypes with Race and Ethnicity}

There are clear racial differences in the frequency of genetic subtypes of ALL. We compared the distribution of genetic subtypes between St Jude Total 15 and MS2003/2010 (Figure 2). The Total 15 cohort has predominantly white, black, and Hispanic races/ethnicities. In contrast, the Ma-Spore cohort is predominantly Chinese, Indian, and Malay. Subtle but important differences exist in the profile of genetic subtypes between these two cohorts, for example in the proportions of DUX4 (4\% in St Jude vs. $12 \%$ in Ma-Spore), $B C R$ - $A B L$-like (12\% in St Jude vs. $2 \%$ in Ma-Spore), PAX5alt (4\% in St Jude vs. $9 \%$ in Ma-Spore), and T-ALL (15\% in St Jude vs. $9 \%$ in Ma-Spore). It is plausible that the differences shown are closely related to the differences in races/ethnicities represented in these two cohorts. Even within the Ma-Spore cohort, notable differences exist amongst the major races. CRLF2, ETV6$R U N X 1$, and T-ALL appear more frequently in Indians, whilst BCR-ABL1 is associated with the Malay race, and ZNF384 and TCF3-PBX1 are more common in the Chinese [11].

A meta-analysis of several studies identified that the frequency of ETV6-RUNX1 fusion in childhood ALL in the Far East (Japan, Korea, Hong Kong, Singaporean Chinese, and Taiwan) was significantly lower than in the West (USA, Germany, Italy, France, and Chile) (15\% vs. $22 \%$ ). Similarly, the frequency of hyperdiploidy in East Asian children was also lower than Western children (15\% vs. 32\%) [12]. TCF3-PBX1 and T-ALL are more frequently identified among African American children compared with other races [13-16]. Children of Hispanic/Latino ethnicity have a higher prevalence of Ph-like ALL, due to a higher prevalence of CRLF2 rearrangements [17]. In fact, it is shown that multiple germline single 
nucleotide polymorphisms predisposing to the development of specific ALL subtypes differ by genetic ancestry, which may account for these subtypes' differing prevalence by race/ethnicity, e.g., GATA3 for Ph-like ALL, BCL11A for TCF3-PBX1, etc. [18-20]. Overall, these racial disparities are usually inferred by comparison across different study groups, and race is usually self-reported. These ethnic differences in biology plausibly contribute to the gap in survival outcomes between racial groups [14-16], and therefore should be investigated comprehensively in a large cohort using a more objective racial delineation.

\section{Association of Genetic Subtypes with NCI Criteria of Age and WBC Count}

The simplest and most widely used risk assignment criteria in childhood ALL are the $\mathrm{NCI}$ criteria, which consist of age and WBC count at presentation [21]. Because the NCI criteria can be consistently reported by any group, they are very useful as a standard comparative tool to compare the treatment outcomes between hospitals and cooperative trials. Infant or adolescent age ( $<1$ or $\geq 10$ years), or high WBC count at diagnosis $\left(\geq 50 \times 10^{9} / \mathrm{L}\right)$ is deemed NCI HR, which carries a worse prognosis than NCI SR patients $[5,21]$. NCI HR patients comprise up to a third of the Ma-Spore cohorts, where despite using MRD for risk assignment, NCI criteria remain highly prognostic [8].

The reason for these seemingly simple NCI criteria remaining as a strong prognostic factor is because ALL molecular subtypes are tightly associated with age and WBC (Figures 3 and 4) [3,4]. Specifically, for children $\leq 1$ year old and $\geq 10$ years old, IRG and HRG are predominant (Figure 3). Similarly, in the group with presenting WBC $\geq 50 \times 10^{9} / \mathrm{L}$, IRG and HRG are also predominant (Figure 4). Taken together, NCI SR patients account for $60 \%$ of FRG, $52 \%$ of IRG, but only $22 \%$ of the HRG group, respectively. Conversely, NCI HR patients account for $40 \%$ of FRG, $48 \%$ of IRG, and $78 \%$ of the HRG group, respectively.

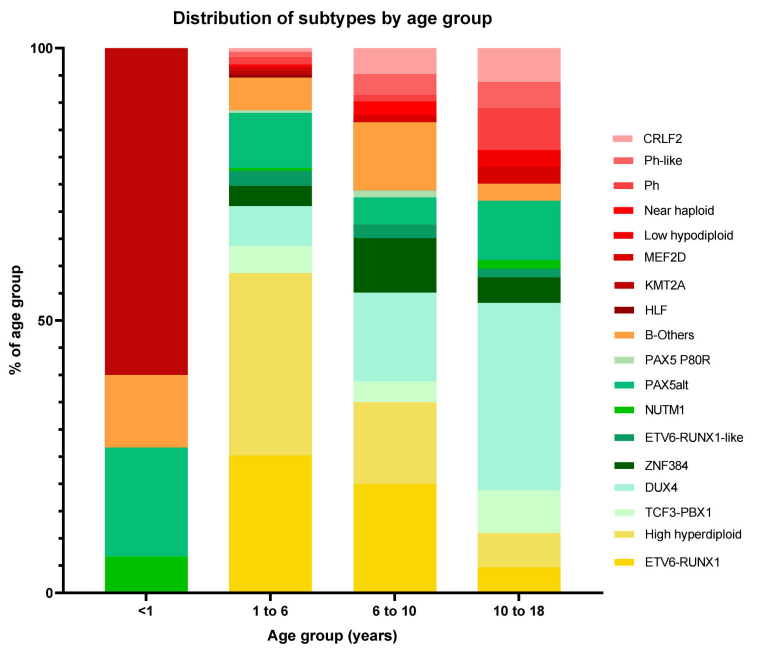

(A)

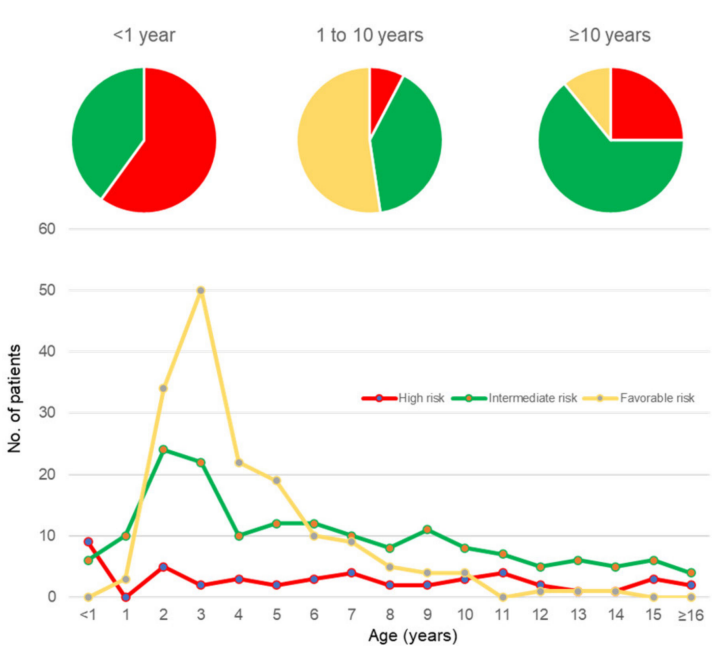

(B)

Figure 3. Association of B-cell acute lymphoblastic leukemia (B-ALL) subtypes with age. (A) Distribution of genetic subtypes by age group, and (B) distribution of genetic risk groups across ages in years. In (A), the proportions of individual subtypes within each age group are plotted, with subtypes summing to $100 \%$ in each category. In (B), the numbers of patients in each genetic risk group are plotted by age. Favorable-risk subtypes are in shades of yellow, intermediate-risk subtypes are in shades of green, and high-risk subtypes are in shades of red. B-others is depicted in orange. Here, the infant group overwhelmingly had KMT2A rearrangements with no favorable-risk genetics. This predominance of the high-risk genetics group in infants accounts for its poor outcome. After infancy, in ages 1-6 years, there is a striking peak of favorable-risk subtypes, such as ETV6-RUNX1 and high hyperdiploidy. Subsequently, the proportion of high-risk subtypes increases with age, and the converse occurs with favorable-risk subtypes. Favorable-risk genetics is rare in adolescents, where there is a predominance of intermediate- and high-risk genetics. Data are adapted from results of RNA-sequencing of children and adolescents with B-ALL in the Malaysia-Singapore cohort. 


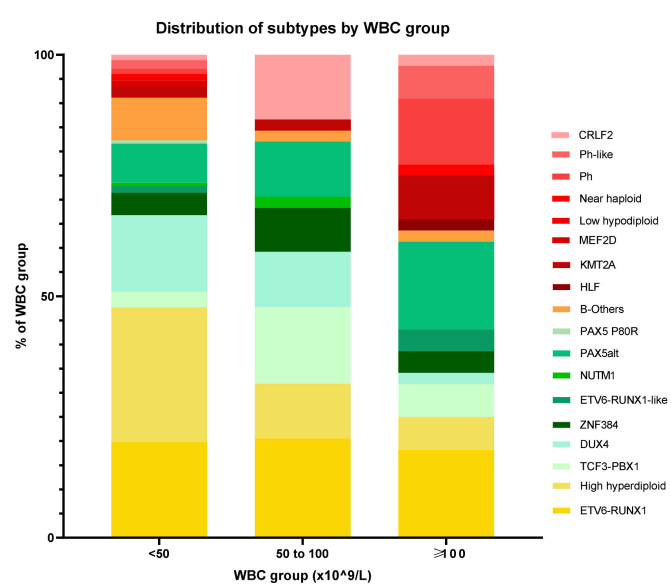

(A)

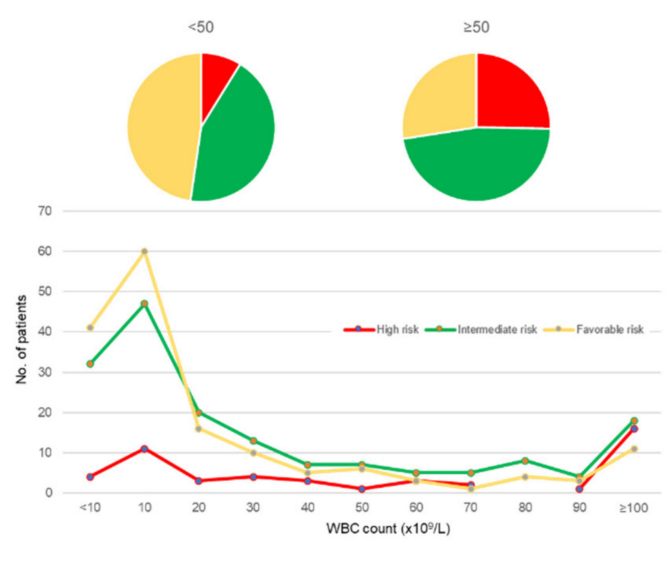

(B)

Figure 4. Association of B-cell acute lymphoblastic leukemia (B-ALL) subtypes with presenting WBC count. (A) Distribution of subtypes by WBC group, and (B) distribution of risk groups across WBC counts. In (A), the proportions of individual subtypes within each WBC group are plotted, with subtypes summing to $100 \%$ in each category. In (B), the numbers of patients in each risk group are plotted by WBC count and the distribution is as shown. Favorable-risk subtypes are in shades of yellow, intermediate-risk subtypes are in shades of green, and high-risk subtypes are in shades of red. B-others is depicted in orange. In general, favorable-risk or intermediate-risk subtypes are associated with low presenting WBC count $\left(<20 \times 10^{9} / \mathrm{L}\right)$, whilst higher-risk subtypes tend to present with a higher WBC, particularly Ph-like ALL, which tends to present with $\mathrm{WBC}>100 \mathrm{k}$. For the $\mathrm{WBC}<50 \mathrm{k}$ group, favorable- and intermediate-risk genetics predominate, accounting for their favorable outcomes. Data are adapted from results of RNA-sequencing of children and adolescents with B-ALL in the Malaysia-Singapore cohort. Abbreviations: WBC, white blood cell count.

\subsection{Infant $A L L$}

Infants ( $<1$ year of age) with ALL have the poorest overall treatment outcomes, which have not improved significantly in recent decades [22,23]. They are uniformly NCI HR because of their age of presentation, and they usually also have high WBC at presentation. KMT2A $(M L L)$ rearrangements, in particular the $\mathrm{t}(4 ; 11)(\mathrm{q} 21 ; \mathrm{q} 23)$ translocation, are most frequent in infants [24]. KMT2A-r ALL has been found to be over-represented in infants (80\% of infants) compared with only $3-5 \%$ in older children [25]. Patients with $t(4 ; 11)$ generally present with hyperleukocytosis, with a high median WBC count $>100,000 / \mu \mathrm{L}[22,25,26]$. WBC count $>300,000 / \mu \mathrm{L}$ confers particularly dismal prognosis $[22,27]$. Diagnosis at younger than 6 months was associated with poorer outcome in multivariable analyses in consecutive Interfant trials [22,23]; congenital ALL (diagnosis within first month of birth) was particularly dismal [28].

\subsection{Adolescent and Young Adult ALL (AYA > 10 Years Old)}

In general, fewer adolescents and young adults (AYA) develop ALL; however, AYA tend to have poorer outcomes. AYA patients comprised $\sim 20 \%$ of the Ma-Spore cohort, amongst which only 11\% were FRG. The tight inverse correlation between AYA and FRG explains why AYA have poorer outcomes (Figure 3). In MS2003/2010, AYA with FRG had similar 5-year EFS and OS to those in the age group of 1-10 years, suggesting that it is not the age that matters but the genetic subtypes represented in that age group.

\section{Association of Genetic Subtypes with MRD and Outcomes}

The quantitation of submicroscopic levels of disease in post-treatment bone marrow samples that are not visible by light microscopy is known as minimal residual disease (MRD). MRD is probably the strongest prognostic factor in ALL [29]. The two reasons why MRD is highly prognostic is because it is (1) very accurate in quantifying the risk of relapse and (2) highly informative ( $>90 \%$ patients have at least one marker). For example, PCR-based MRD used in Ma-Spore and Europe is informative in $90 \%$ of patients while flow-based MRD used in the USA is informative in $95 \%$ of patients. Currently, the level of MRD negativity is defined as $0.01 \%$ (or 1 in 10,000 cells). With the advent of NGS, 
sensitivity reaches $0.001 \%$ ( 1 in 100,000 cells) or better, and also allows for monitoring of all tumor-related sequences simultaneously. This extreme sensitivity allows for an even more refined risk stratification, by being able to identify a truly favorable group (i.e., those with truly extremely low or no disease), as well as being able to pick up early clonal evolution (new and low levels of disease) and possible eventual relapse [30-32].

Post-treatment MRD sums the combined effects of three critical aspects of ALL treatment in determining outcome: (1) genetic subtype, (2) effectiveness of chemotherapy given, and (3) host genetics affecting drug metabolism. For this reason, MRD is the strongest prognostic factor in ALL. However, because MRD is the combined effect of three factors, it is still dependent on genetic subtypes in predicting relapse.

Previously, cytogenetics and oncogene fusion screening (mainly ETV6-RUNX1, TCF3$P B X 1, B C R-A B L 1$, and $K M T 2 A-A F 4)$ were informative in characterizing genetic subtype in only $50 \%$ of patients. Yet despite being informative in only half of patients, conventional genetic subtypes are highly prognostic, even in the era of MRD. Using RNA-Seq, we can now assign a specific genetic group for up to $93 \%$ of patients. With information on risk of relapse in $93 \%$ of patients, RNA-Seq genetic subtype may probably be more informative than MRD. Because RNA-Seq subtype is available early (usually before EOI), necessary alternative intervention (e.g., intensification, immunotherapy, etc.) can be brought forward. In addition, for the $A B L$-class fusion group, early use of a tyrosine kinase inhibitor, such as imatinib, dasatinib, or even ponatinib, can improve complete remission rates and outcomes.

In the HRG group of the Ma-Spore cohorts, MRD remained prognostically important ( $p=0.015$ for EFS, $p=0.28$ for OS, Figure 5). HRG patients who are EOI MRD-negative, when treated on the Ma-Spore HR chemotherapy arm, do well without any need for HSCT. However, HRG patients who are EOI MRD-positive (MRD-IR or MRD-HR) fare poorly: their 5-year EFS is <50\%. In MS2020, HRG patients who are both EOI and middle-ofconsolidation (MOC, week 8) MRD-positive qualify for chimeric antigen receptor (CAR)-T cell therapy or HSCT in first CR.

A

FRG subtypes
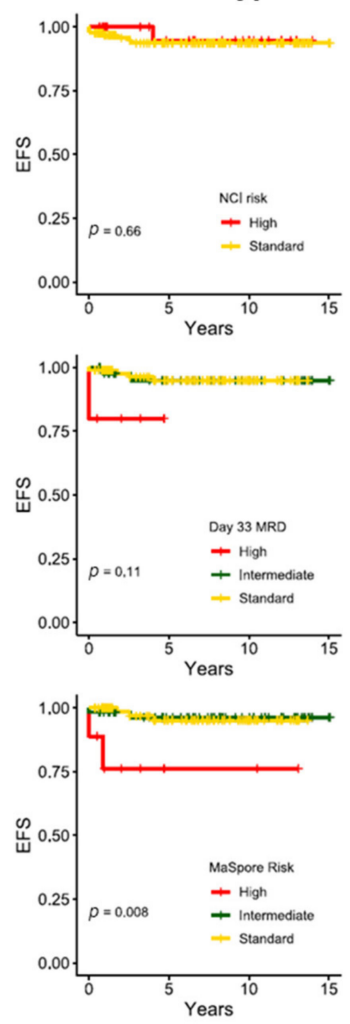
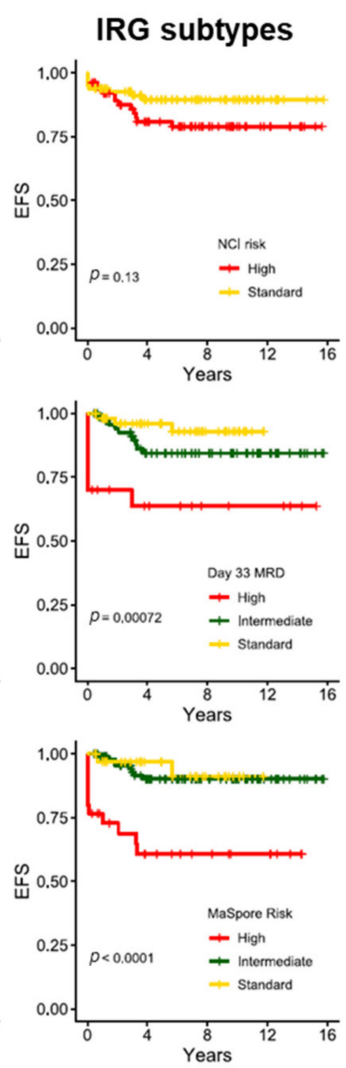

HRG subtypes
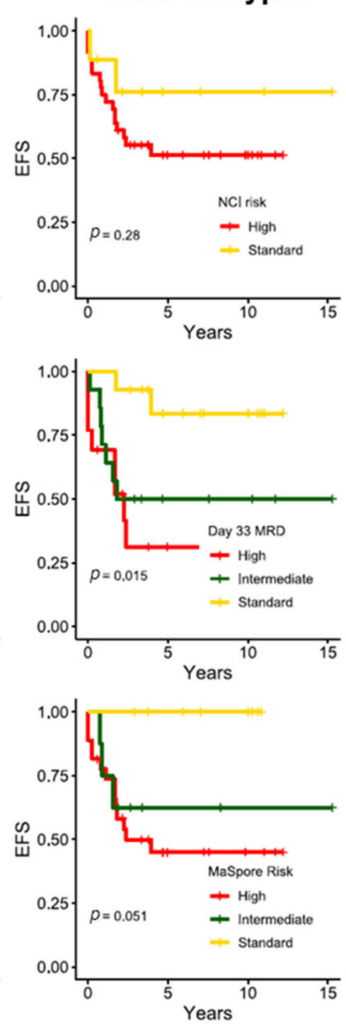

Figure 5. Cont. 

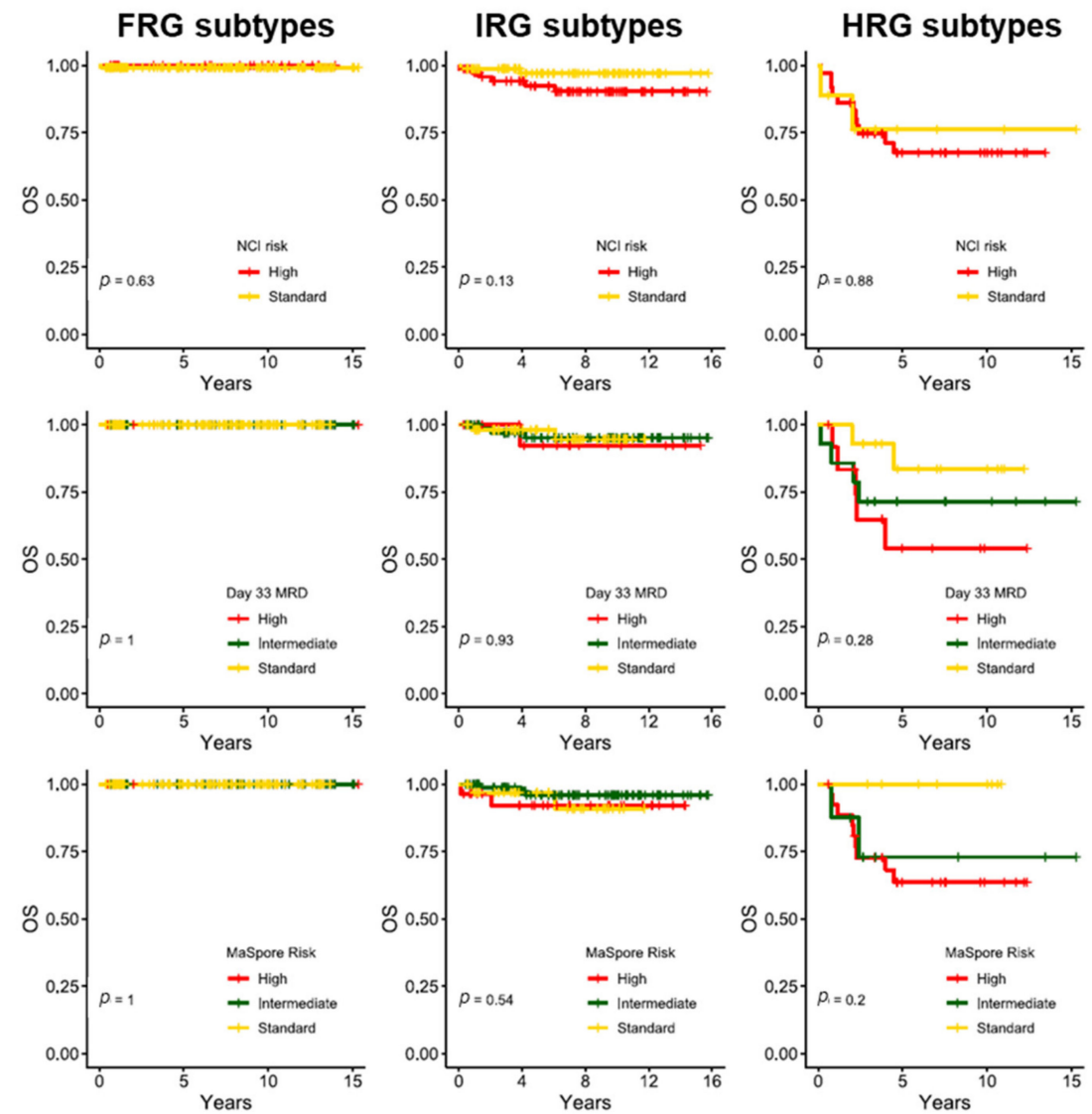

Figure 5. Treatment outcomes for genetic subtype risk groups with additional stratification by various prognostic markers in the Malaysia-Singapore cohort. (A) Event-free survival, and (B) overall survival. Genetic subtypes are defined by RNA-sequencing, and risk stratification is based on results from Malaysia-Singapore ALL trials. Favorable-risk (FRG) subtypes include hyperdiploidy and ETV6-RUNX1. Intermediate-risk (IRG) subtypes include DUX4, TCF3-PBX1, ETV6-RUNX1-like, ZNF384, ZNF384-like, PAX5alt, PAX5 P80R, IGH-CEBPE, NUTM1, and B-Others. High-risk subtypes (IRG) include TCF3-HLF, BCR-ABL, BCR-ABL-like, hypodiploidy, near-haploid, MEF2D, CRLF2, and KMT2A rearrangements. Ma-Spore risk classification integrates NCI risk group and Day 33 MRD. In the low-risk subtypes, outcomes are exceedingly favorable throughout, regardless of other prognostic factors. Conversely, these other factors further delineate the prognosis of higher-risk subtypes, especially with regards to EFS, highlighting the interplay between subtypes and these factors, and also underscoring the importance of integrating all these factors into risk stratification.

For IRG, EOI MRD remained the most significant prognostic factor for EFS ( $p=7.2$ $\left.\times 10^{-4}\right)$. In particular, IRG patients who are EOI MRD HR $(>1 \%)$ have dismal outcomes (5-year EFS 40\%). In MS2020, IRG with both high EOI (MRD $\geq 1 \%$ ) and high MOC MRD (week $8 \geq 0.1 \%$ ) also qualify for CAR-T cell therapy or HSCT in first CR. IRG patients who are EOI MRD SR have good 5-year EFS of $90-95 \%$, which is equivalent to FRG patients. Therefore, these children can probably be treated with de-intensified chemotherapy.

For the FRG group, even if patients had low EOI MRD positivity $(<0.1 \%)$, their 5-year EFS remained excellent. For this reason, they also qualify for treatment de-intensification. Only in high EOI MRD $(\geq 1 \%)$ is treatment intensification truly indicated. For the Ma-Spore trials, in the rare situation where EOC MRD remains high ( $\geq 0.1 \%)$, FRG patients qualify for CAR-T cell therapy or HSCT in first CR because these patients usually have a poorer 5 -year EFS of $\sim 75 \%$.

Below, we summarize the specific clinical features associated with each subtype. 


\subsection{ETV6-RUNX1 and Hyperdiploidy}

ETV6-RUNX1 and hyperdiploidy both have excellent outcomes (Table 2). However, these subtypes do differ in their MRD response: ETV6-RUNX1 has more rapid MRD clearance [33]. In the Total 15 study, 58\% of the patients with ETV6-RUNX1 fusion had MRD $<0.01 \%$ at Day 19 , compared with $44 \%$ of hyperdiploid diseases [34]. Similarly, in Total $16,54 \%$ of ETV6-RUNX1 had MRD $<0.01 \%$ at Day 15 compared with $31 \%$ of hyperdiploid cases. The same trend is seen for COG [35,36], UKALL2003 [7], and MS2003/2010 [8,9]. Overall, both ETV6-RUNX1 and hyperdiploid ALL have excellent outcomes with contemporary 5-year EFS and OS exceeding 90\% [34,37,38]. In MS2003/2010, all ETV6-RUNX1 and hyperdiploid cases received a de-intensified, three-drug, dexamethasone-based induction without anthracyclines, with excellent results.

Table 2. EOI MRD response in favorable-risk genetic risk subtypes. ETV6-RUNX1 has the second most rapid MRD response among all the genetic subgroups after TCF3-PBX1.

\begin{tabular}{cccccc}
\hline EOI MRD < $\mathbf{0 . 0 1 \%}$ & $\begin{array}{c}\text { Total 15 } \\
\text { (Day 19) }\end{array}$ & $\begin{array}{c}\text { Total 16 } \\
\text { (Day 15) }\end{array}$ & COG & UKALL 2003 & MS2003/2010 \\
\hline ETV6-RUNX1 & $58 \%$ & $54 \%$ & $90 \%$ & $73 \%$ & $76 \%$ \\
\hline Hyperdiploidy & $44 \%$ & $31 \%$ & $80 \%$ & $52 \%$ & $54 \%$ \\
\hline
\end{tabular}

\subsection{PBX1 Fusions Including TCF3-PBX1}

TCF3-PBX1, with $\mathrm{t}(1 ; 19)(\mathrm{q} 23 ; \mathrm{p} 13)$ translocation, is more commonly found in children TCF3-PBX1 accounts for $\sim 5 \%$ of childhood ALL, but only $1 \%$ in adults [3,39]. TCF3-PBX1 generally presents with higher WBC (median $56,000 / \mu \mathrm{L}$ ) [40,41]. TCF3-PBX1 is also more common among African Americans. Rarely, other than TCF3, PBX1 may fuse with another partner. These rare fusions involving PBX1 and other partners have similar GEP as TCF3$P B X 1$ and are classified together under the PBX1 fusion group.

Historically, in the era of lower-intensity therapy, TCF3-PBX1 ALL had poorer outcomes [42]. With more intensive chemotherapy, the outcomes for TCF3-PBX1 have improved considerably. In MS2003/2010, PBX1 patients have a low 5-year CIR of 5.6\%. Researchers in Hong Kong reported no relapse and 100\% 5-year survival in 30 TCF3-PBX1 patients treated from 1997 to 2016 [43].

The UKALL group reported that TCF3-PBX1 has the most rapid clearance of MRD [33], with $>85 \%$ of patients having an EOI MRD level $\leq 0.01 \%$ [44,45]. In MS2003/2010, where most patients received three-drug induction, TCF3-PBX1 patients achieved MRD negativity in $53 \%$ and $94 \%$ of cases by EOI and EOC, respectively. However, in TCF3-PBX1, failure to achieve MRD negativity by EOC predicts a poorer outcome.

In Total 15, where cranial irradiation is omitted, the St Jude investigators reported an increased risk of central nervous system (CNS) relapse $(9.0 \pm 5.1 \%)$ [46]. With two additional intensified intrathecal therapies during induction and PEG L-asparaginase intensification in Total 16, no TCF3-PBX1 patients developed CNS relapse. The 5-year CIR of TCF3-PBX1 in Total 16 was $6 \%$, with an intermediate 5-year EFS and OS of $88 \%$ because of transplant-related mortality [47].

Overall, with sufficiently intensive therapy such as the medium-risk arm of ALL$B F M, T C F 3-P B X 1$ patients have excellent outcomes. In general, many groups such as Ma-Spore are de-intensifying therapy for EOI MRD-negative patients. Therefore, for TCF3$P B X 1$ patients who are EOI MRD-negative, de-intensification of therapy can be attempted. However, despite its overall favorable outcome as a genetic subtype, de-intensifying therapy for all TCF3-PBX1 patients may be risky. This is because of the historically poorer outcomes of TCF3-PBX1 with less intensive regimens, and also because relapses of TCF3$P B X 1$ are difficult to salvage even with HSCT. It is not clear yet whether CAR-T cell therapy will be able to effectively salvage TCF3-PBX1 relapses. Although they have a low 5-year CIR of only 5.6\% in MS2003/2010, we still recommend that TCF3-PBX1 be classified as IRG. 
MS2020 will only de-intensify therapy for TCF3-PBX1 patients who are EOI MRD-negative, which accounts for only $53 \%$ of the TCF3-PBX1 cohort.

\subsection{ZNF384-Rearranged (ZNF384- $r$ )}

ZNF384- $r$ is found in $1-6 \%$ of childhood B-ALL and $5-15 \%$ of adult B-ALL cases $[5,48]$. It is found more frequently among older children $[48,49]$, with a median age of 6.8 years in MS2003/2010. The median WBC of patients at presentation is slightly higher at $37,000 / \mu \mathrm{L}$ in MS2003/2010, similar to another report. This subtype also appears to be more common in Asians [50].

For ZNF384-r, MS2003/2010 reported a 5-year CIR of 6.3\%, 5-year EFS of 83\%, and 5 -year OS of $93 \%$, which is similar to the Ponte Di Legno group [51] with 5-year EFS of $84 \%$ and OS of $91 \%$. However, in MS2003/2010, the kinetics of MRD response for ZNF384r is slow. Only $18 \%$ of ZNF384 cases were EOI MRD-negative. This slow response improved by EOC, with 77\% negative in EOC MRD. Treatment response and outcomes varied with different rearrangement partners of ZNF384. Patients with EP300-ZNF384 ALL had better prednisolone response [50] and EFS than other ZNF384-rearranged cases [48]. Of note, the relapse of patients with TCF3-ZNF384 and TAF15-ZNF384 rearrangements can occur late, several years after the completion of treatment $[48,50,52]$.

\subsection{PAX5}

PAX5-rearranged ALL comprises two genetic subgroups: PAX5-P80R and, more commonly, PAX5alt [53]. These PAX5-rearranged cases are usually older. Gu et al. found that the median ages at diagnosis for PAX5-P80R and PAX5alt ALL subjects were 22.0 years and 15.4 years, respectively [3]. The proportion of $P A X 5-P 80 R$ cases increased with age even into adulthood, while PAX5-alt cases peaked at adolescence [3]. PAX5alt has higher presenting WBC $(>50,000 / \mu \mathrm{L})$. In fact, this effect seemed to be additive, where patients showing more than one PAX5 aberration had an ever higher WBC count compared with patients with only one PAX5 abnormality [53].

$\mathrm{Gu}$ et al. reported that $\sim 70 \%$ PAX5alt patients achieved EOI MRD $<0.01 \%$, indicating a relatively good response to treatment [3]. However, in children, the outcome in COG AALL0232 is only intermediate, with OS of $\sim 75 \%$. In adults, the outcome is poor, with OS of $42 \%$. By comparison, the PAX5 P80R subtype generally responds rapidly to therapy, with $>90 \%$ of patients achieving MRD $<0.01 \%$ at EOI [3], although outcomes vary in different studies. In a German cohort reported by Bastian et al. with both pediatric and adult patients, this subtype had an OS of $80 \%$ [54]. In adults, PAX5 P80R ALL had a relatively favorable outcome compared with PAX5alt, with an OS of 62\% [3].

In St Jude Total 16, PAX5alt had an intermediate outcome with a 5-year CIR, EFS, and OS of $17 \%, 83 \%$, and $100 \%$. In MS2003/2010, 39\% of PAX5alt have negative EOI MRD. These PAX5alt patients who are EOI MRD-negative do well. However, we noticed a poorer outcome for PAX5alt who are IKZF1 ${ }^{\text {del }}$ (see Section 6 below).

\subsection{ETV6-RUNX1-Like}

More recently discovered is the ETV6-RUNX1-like subtype, accounting for $\sim 3 \%$ of B-ALL. Despite a lack of ETV6-RUNX1 fusion, such cases clustered with the ETV6-RUNX1positive cases [55]. ETV6-RUNX1-like ALL seems to occur almost exclusively in children and adolescents, and presents at a similar median age to ETV6-RUNX1 ALL at 3-5 years of age $[3,55,56]$. Similar to ETV6-RUNX1, ETV6-RUNX1-like ALL does not have elevated presenting WBC $[38,56]$. Surprisingly, although it has a similar GEP to ETV6-RUNX1, ETV6-RUNX1-like has poorer outcomes. In fact, in the recent Total 16 study, ETV6-RUNX1like patients had amongst the highest relapse rates (5-year CIR 22\%) [57], consistent with the poor outcomes from earlier reports [55].

ETV6-RUNX1-like patients commonly have $I K Z F 1^{d e l}$. Because of the small numbers, it is unclear in MS2003/2010 whether IKZF1 ${ }^{\text {del }}$ conferred an adverse outcome for ETV6- 
RUNX1-like. In MS2003/2010, ETV6-RUNX1-like has 5-year CIR and OS of 13\% and 89\%, respectively. For this reason, ETV6-RUNX1-like may benefit from higher-intensity therapy.

\subsection{DUX4}

The DUX4 subtype is characterized by the rearrangement of the DUX4 gene to the IGH locus. This rearrangement brings DUX4 close to the IGH enhancer E $\mu$, resulting in a distinctive GEP with exceedingly high expression of DUX4. It is also associated with transcriptional deregulation (usually deletion) of ERG and $I K Z F 1^{\text {del }}(63 \%$ and $28 \%$, respectively) [58,59]. DUX4 patients tend to be slightly older (median age 9.8 y in MaSpore) [60-62], with low white cell counts (median 10,000/ $\mu \mathrm{L}$ ) [60,63,64].

Of the IRG group, DUX4 ALL has a very notably peculiar MRD response. In Total 16, where MRD was flow-based, all DUX4 patients were MRD-positive at Day 15 of induction, with $50 \%$ having high MRD >1\% [57]. However, by EOI (Day 42), 95\% became MRDnegative. In Total $16,40 \%$ of DUX4 were treated on low-risk and $60 \%$ on standard-risk arms, and the outcomes for DUX4 were excellent (5-year EFS 95\% with no relapses). In contrast, in MS2003/20110 which used PCR MRD, 74\% of DUX4 were EOI (Day 33) MRDpositive, with 25\% EOI MRD HR (>1\%). In the AIEOP-BFM ALL 2009 study, around 90\% of the DUX4 patients had positive EOI or EOC MRD [65]. Despite this, DUX4 in AIEOP-BFM 2009 also had very favorable outcomes. This favorable outcome is similar to MS2003/2010, where most patients were treated on the IR or HR arm, including HSCT in first CR. In MS2003/2010, the 5-year CIR, EFS, and OS were 9\%, 91\%, and 98\%, respectively.

As the induction therapies for St Jude, AIEOP-BFM, and Ma-Spore are not very different, the discordance of EOI MRD is surprising and significant. We postulate that this difference in EOI MRD is because of differences in MRD detected by flow cytometry and PCR. Specifically, compared with PCR MRD, flow MRD is probably more adept at tracking the response of DUX4 ALL. One plausible reason is the tendency for switching of DUX4 leukemia clones to a monocytic lineage [66]. Flow MRD can detect and exclude these monocytic-switched cells. Since these monocytic-switched cells do not contribute to relapse, flow MRD is probably more accurate in quantifying the true leukemic MRD burden. On the other hand, PCR-based MRD cannot distinguish between these monocytic-switched cells and DUX4 leukemia cells as they both carry the same clonal Ig/TCR marker. Taken together, we believe that PCR-based MRD may overestimate the potential of relapse of DUX4 patients. In fact, for DUX4, we find that EOI MRD based on PCR Ig/TCR is not prognostic of outcome.

Interestingly, ERG deletion, which occurs almost exclusively in the DUX4 subtype, is associated with better MRD response and outcome [67]. IKZF1 $1^{\text {del }}$ as no adverse effect on DUX4. Overall, most trial groups consistently report excellent results for DUX4, with EFS and OS usually exceeding 90\% [3]. Although now considered by some trials to be favorable [57], due to seemingly poor MRD response, DUX4 are often treated as highrisk $[57,65]$. Given their excellent outcomes, this raises the question as to whether these patients are actually over-treated. The possibility of de-intensifying therapy in this group needs to be examined carefully. To begin addressing this question prospectively, in MS2020, DUX4 will be treated on the IR arm regardless of EOI MRD and will only undergo HSCT if MRD levels are rising despite chemotherapy.

\subsection{Philadelphia (Ph, BCR-ABL1)-Positive}

Philadelphia chromosome (Ph) ALL, with the BCR-ABL1 fusion, is one of the quintessential high-risk ALL subtypes. It is defined by $\mathrm{t}(9 ; 22)$. The incidence of Ph ALL increases with age $>10$ years; it accounts for $2 \%$ to $5 \%$ of childhood ALL but $25 \%$ of adult ALL. With standard 4-drug ALL induction therapy, there is an exceedingly high induction failure rate of $11 \%$ compared with the $2 \%$ to $3 \%$ seen among children with non-Ph ALL [68]. Historically, even with HSCT in first CR, EFS rates were dismal, ranging from $28 \%$ to $32 \%$ [69].

Tyrosine kinase inhibitors (TKIs) have dramatically changed the treatment landscape for Ph ALL, both in children and adults. The addition of imatinib to combination chemother- 
apy doubled EFS rates, compared with those who did not receive imatinib [70,71]. Recently, a large randomized trial in China comparing dasatinib and imatinib showed the superiority of dasatinib with 4-year EFS and OS rates of $71.0 \%$ and $88.4 \%$, respectively, compared with $48.9 \%$ and $69.2 \%$, respectively, for imatinib [72]. Notably, EOI MRD negativity of dasatinib and imatinib was similar. For Ma-Spore, the addition of imatinib to the high-risk chemotherapy backbone reduced the 5-year CIR of Ph ALL from 58\% in MS2003 to 19\% in MS2010. Although the toxicity of therapy also increased, the 5-year OS in MS2010 still improved significantly for Ph ALL.

In general, most trial groups regard Ph ALL as high-risk or very high-risk, and are treated on a Ph ALL-specific protocol. The European study groups such as UKALL [73,74], AEIOP-BFM [75], and DCOG [37] enrolled Ph ALL in separate protocol EsPhALL [70]. Similarly, the COG considered Ph ALL as "very high risk", and enrolled these patients in the separate study AALL0031 [71]. Due to concerns about treatment-related mortality from intensive chemotherapy plus TKI, MS2020 will enroll Ph ALL on three-drug induction with a TKI (either dasatinib or imatinib). EOI MRD-negative Ph ALL patients will continue on TKI plus standard-risk, reduced intensity chemotherapy while EOI MRD-positive patients qualify for CAR-T or HSCT in first CR. MS2020 aims to use an intensive TKI on top of a less intensive chemotherapy backbone.

\subsection{BCR-ABL-Like (Ph-like) with or without CRLF2 Rearrangements}

$B C R-A B L$-like, or Ph-like, ALL is characterized by a spectrum of diverse genetic alterations and has a similar transcriptional profile to Ph-positive ALL but without the BCR-ABL1 fusion [76]. The prevalence of Ph-like ALL increases significantly with age and NCI risk group, from $10 \%$ among SR children and $13 \%$ for HR children, to $21 \%$ among adolescents, and $27 \%$ among young adults [77]. While the prevalence of $B C R-A B L$ ALL rises progressively with age, Ph-like ALL differs in that it peaks in young adulthood [5]. Both Ph and Ph-like ALL are usually associated with higher leukocyte counts at presentation [77-79].

Similar to Ph ALL, Ph-like ALL typically has high EOI and EOC MRD. Ph-like ALL also has higher rates of treatment failure compared with non-Ph-like ALL patients. For Ph-like ALL, the 5-year EFS and OS rates in children and AYA are $58 \%$ and $73 \%$ for children, and $41 \%$ and $66 \%$ for AYA, respectively $[77,80,81]$. Survival is particularly poor for Ph-like patients with elevated EOI MRD [80]. The higher prevalence of Ph-like ALL in AYA may partly explain the adverse outcomes in this age group.

Ph-like ALL is characterized by multiple genomic alterations, and the majority of alterations can be targeted effectively with ABL (e.g., dasatinib) or JAK inhibition (e.g., ruxolitinib). Currently, the inferior survival for Ph-like ALL appears to occur regardless of the underlying genomic alteration. A multiple combinatorial approach to chemotherapy with targeted therapies is currently being tested in frontline studies, giving further hope in the treatment of this high-risk subtype [82]. For MS2020, Ph-like ALL with ABL-class fusion will be treated with dasatinib or imatinib plus SR chemotherapy backbone. As RNA-Seq results may return only at the EOI, Ph-like ALL patients will qualify for HSCT or CAR-T therapy if MRD remains positive at week 8 (MOC).

Ph-like ALL is frequently associated with CRLF2 rearrangements, and IGH-CRLF2 rearrangement accounts for almost $50 \%$ of Ph-like ALL in AYA and adults [82]. Patients with CRLF2 rearrangements had poorer treatment outcomes in general compared with those without. In particular, those with CRLF2-PY2R8 rearrangements had the most inferior EFS (5-year EFS of $57 \%$ vs. $83 \%$ for other B-ALL) and significantly increased CIR ( $43 \%$ vs. $14 \%$ for other B-ALL) $[17,83,84]$. In the Ma-Spore studies, we chose to separate $B C R$ ABL1-like ALL into two distinct groups based on the presence of CRLF2 expression, and on ABL-class fusion since it is targetable.

CRLF2 rearrangements are most common in Ph-like and Down syndrome-associated ALL, but also occur without the transcriptional signature of Ph-like ALL [85]. CRLF2 is overexpressed in approximately $15 \%$ of adult and high-risk pediatric B-ALL, and is associated with Hispanic ethnicity $[85,86]$. These rearrangements are age-dependent, with P2RY8-CRLF2 
associated with younger age (median 4 years) and IGH-CRLF2 associated with older age (median 8 years) [87-89]. Although CRLF2 rearrangements have not been found to be associated with WBC count at diagnosis in general [89], high-risk patients with CRLF2 rearrangements had a higher median WBC than those without $\left(92 \times 10^{9} / \mathrm{L}\right.$ vs. $\left.60 \times 10^{9} / \mathrm{L}\right)$ [17].

\section{9. $M E F 2 D$}

Myocyte enhancer factor 2D (MEF2D), another recently discovered subtype, is characterized by multiple fusion partners, the most common being MEF2D-BCL9. MEF2D rearrangement occurs in approximately $1-4 \%$ of B-ALL in children and $6-7 \%$ of adult ALL $[1,3,90]$. This subtype occurs more frequently in older children and adolescents (median of 9-14 years) [1,91,92]. These patients also usually have elevated WBC counts (median $>20,000 / \mathrm{mL}$ ) at presentation and, as a result, are mostly classified as NCI high risk [92].

Although MEF2D-rearranged ALL is uncommon (1\% in Ma-Spore), they have an inferior outcome. An analysis of children enrolled on the AALL0232 study of high-risk pre-B ALL showed that the 5-year event-free survival (EFS) of MEF2D-rearranged ALL was $71.6 \%$, compared with $87.3 \%$ for other pre-B ALL cases. However, in this same study, $M E F 2 D$ rearrangements lost prognostic impact after correcting for age, sex, and WBC. In a smaller cohort of four patients with $M E F 2 D-B C L 9$ rearrangement, all were noted to have chemotherapy resistance and very early relapse, with statistically significantly poorer EFS and OS rates for MEF2D patients [93]. Similarly, an analysis of a small cohort showed that although there was no poor steroid response associated with this subtype, there was a 53.3\% relapse rate, all of whom died [92]. In Total 16, there were only three MEF2D-r ALL with 5year CIR, EFS, and OS of 33\%, $67 \%$, and $67 \%$, respectively. In MS2003/2020, all four MEF2D$r$ patients were alive and disease-free. Because it is uncommon, it is only retrospective pooling of a large number of $M E F 2 D$-rearranged cases by groups, such as the Ponte de Legno group, that allows us to accurately determine if they have poorer outcomes [91]. Increased expression of MEF2D is associated with activation of HDAC9 [90,91], which in turn may confer sensitivity to histone deacetylase inhibitor treatment [94], such as vorinostat, and proteasome inhibitor treatment, such as bortezomib [91].

\subsection{KMT2A-Rearranged/MLL}

KMT2A-rearranged ALL is a very high-risk disease with poor response to treatment. Disappointingly, there has not been much improvement in outcome for KMT2A-r ALL. The most recent studies have indicated only modest improvement (4-year EFS of $40-50 \%$ and OS of $50-55 \%)$, compared with $20-40 \%$ historically $[22,27,95,96]$. The recently published Interfant-06 study showed only $\sim 20 \%$ and $\sim 40 \%$ of patients achieved MRD negativity at EOI and EOC, respectively [95]. The poor outcomes are due to intrinsic resistance of KMT2A-r blasts, which often have (in vitro) resistance to important chemotherapeutic drugs such as prednisone and l-asparaginase, although they typically have acute sensitivity to cytarabine [97]. Although most patients $(\sim 80-90 \%)$ will go into remission initially, a high proportion (50-60\%) of them will relapse, most commonly in the bone marrow [27].

In general, there is no significant association between relapse or survival in KMT2A-r ALL and any particular fusion partner. Therefore, most current clinical risk stratifications do not take the fusion partner into account $[25,96,98]$. Although HSCT plays a strong role in consolidation therapy for most high-risk leukemias and T-ALL, this is not the case for KMT2A-r ALL where HSCT has not yet been shown to be of benefit in general [99-101]. However, the Interfant-99 ALL trial identified a small subgroup of infants with additional poor prognostic factors where HSCT appeared to be valuable [22]. This subtype is universally stratified as high-risk to receive intensified therapy [35-37,73-75,102], or similar to $\mathrm{Ph}-\mathrm{ALL}$, where it is managed as separate protocols [95,103].

It is not clear whether CAR-T CD19 therapy will be a game changer for KMT2A- $r$ ALL. This is because KMT2A-r ALL may relapse with monocytic switch and loss of CD19 expression. 


\subsection{Low-Hypodiploid and Near-Haploid}

Near-haploid (24-30 chromosomes) and low-hypodiploid (31-39 chromosomes) are rare; they are each seen in $\sim 0.5 \%$ of childhood ALL [104-107]. An interesting frequent phenomenon in hypodiploid ALL is doubling of the chromosomal content, resulting in clones with 50 to 78 chromosomes, masquerading as masked hyperdiploidy [107]. Interestingly, near-haploidy has never been reported in adult ALL, whereas $\sim 4 \%$ of cases harbor low hypodiploidy $[105,107,108]$. The age profiles of near-haploidy and low hypodiploidy differ, with the former being restricted solely to childhood/adolescence and the latter becoming more frequent with increasing age. All reported near-haploid ALL cases have been 1 to 19 years old at diagnosis, with a median age around 5 years. On the other hand, low hypodiploidy occurs at all ages and is characterized by an older pediatric age group with a median age of 13-15 years [108-110]. Both groups display relatively low white blood cell counts at diagnosis, with median blood counts usually $<10 \times 10^{9} / \mathrm{L}[105,106,109,110]$.

Similar to infant ALL, children with hypodiploid and near-haploid ALL have continued to fare poorly in recent decades. MRD response is generally unfavorable, with only $50 \%$ achieving EOI MRD $<0.01 \%$ [109]. In terms of survival, the COG AALL0031 study demonstrated a 4 -year OS rate of $54 \%$ for this group [103]. More recently, a multicenter retrospective study on 306 patients (representing 16 cooperative study groups) did not show much difference, with 5-year EFS of $55 \%$ and an OS rate of $61 \%$, even with MRD-directed therapy [109]. Expectedly, a high proportion of patients had poor early response by morphologic examination and/or high MRD after induction therapy. Similar to infant ALL, transplantation did not improve outcome compared with chemotherapy alone, especially among the subgroup of patients who achieved a negative MRD status $[104,111]$. Near-haploid ALL is historically thought to have poorer outcomes than hypodiploid ALL, with EFS reported to be $20-40 \%$ [106,107], although evidence is conflicting with some trial groups reporting no difference between outcomes for hypodiploidy and near-haploidy [112]. The UKALL [73,74] and NOPHO [113] studies stratified this subtype as high-risk while COG included it as one of the very high-risk subtypes in the AALL0031 study [103].

In children, low-hypodiploid ALL is associated with TP53 germline mutation, which confers a poorer outcome regardless of genetic subtype [114].

\subsection{HLF}

This particular rare subtype portends an extremely poor prognosis; it is one of the subtypes that is regarded as almost incurable. This subtype has translocation $t(17 ; 19)(q 22 ; p 13)$, resulting in the fusion gene TCF3-HLF, which is typically associated with treatment failure, relapse, and death within two years from diagnosis [115-117]. Interestingly, in vitro studies show exquisite sensitivity of TCF3-HLF leukemic cells to the BCL2 inhibitor venetoclax (ABT-199), suggesting a new therapeutic option for this otherwise fatal subtype [117]. Additionally, a recent report has described the successful use of CD-19 directed immunotherapy with blinatumumab and SCT to induce durable remissions in four out of nine patients [116].

Due to the low frequency of this subtype, it is rarely considered in risk stratification, but for those that do, e.g., the UKALL 2003 study, TCF3-HLF is uniformly stratified as high-risk [74].

\subsection{3. iAMP21}

Intrachromosomal amplification of chromosome 21 (iAMP21), a complex chromosomal abnormality, defines a novel cytogenetic subgroup of B-ALL with an unusual mechanism of chromothripsis behind its formation [118]. Patients with iAMP21 tend to be older (with median age 9 years), and they usually present with a low white cell count (median of $5 \times 10^{9} / \mathrm{L}$ ) [119,120]. iAMP21 is rare, accounting for $1 \%$ of childhood ALL. It is best detected using the RUNX1 FISH probe. As the Ma-Spore study group does not use FISH, we have not consistently found $i A M P 21$ in our patient group. 
Although patients with $i A M P 21$ were more likely to be MRD-positive at EOI [120], interestingly the data on prognostic impact of MRD in these patients are conflicting thus far. The Berlin Frankfurt Munster group found that iAMP21 patients who were MRD-positive had an inferior outcome compared with MRD-negative patients [121], whereas results from COG suggested that MRD was generally not of prognostic relevance, with the exception of a subgroup of SR patients [120]. However, trials uniformly found that patients with iAMP21 fared poorly when treated on a standard-risk backbone and this was abrogated by intensification of treatment on a high-risk backbone (EFS $29 \%$ to $78 \%$, OS $67 \%$ to $89 \%$ in the UKALL trial group) $[119,120,122]$.

\section{IKZF1 Deletion and Interactions with Genetic Subtypes}

Alteration in the IKZF1 gene, which regulates both B and T lymphoid differentiation, has emerged as an important prognostic factor in ALL. Somatic deletions of the IKZF1 gene $\left(I K Z F 1^{d e l}\right)$ confer a significantly worse outcome for ALL [9,123-126]. The availability of the MRC Holland multiplex ligation probe-dependent amplification (MLPA), which is easy to use and affordable, has democratized screening for deletions of IKZF1 ${ }^{\text {del }}$ [9]. Using the MLPA kit, IKZF1 ${ }^{\text {del }}$ patients in MS2010 were upstaged to the next higher risk group, and thus treatment intensity level. This upstaging, together with use of imatinib in $\mathrm{Ph}$ ALL-positive cases, lowered the 5-y CIR from 30\% to 8\% and improved 5-year OS from $70 \%$ to $92 \%$.

Somatic IKZF1 ${ }^{d e l}$ occurs in $\sim 15 \%$ in pediatric ALL cases [4,127]. Clinically, IKZF1 ${ }^{\text {del }}$ is typically associated with older age at diagnosis, higher WBC, and higher EOI MRD [9,123-126]. Whole-gene deletions are more prevalent among children aged 1-9 years old with lower WBC counts (median of $7.9 \times 10^{9} \mathrm{~L}$ ), as compared with intragenic deletions [128-130].

Overall, IKZF1 ${ }^{\text {del }}$ confers an unfavorable outcome [9,125,131-133]; 5-y EFS reaches as low as 39\% (vs. 73\% for IKZF1-neg patients, $p<0.0001$ ) [124], 8-year OS as low as $56 \%$ (vs. 91.0\% for IKZF1-neg patients, $p<0.001$ ) [134], and 5-year CIR as high as $73 \%$ (vs. $25 \%$ for IKZF1-neg patients, $p<0.0001$ ) [124]. This was also true for children with Down syndrome and ALL, where IKZF1 ${ }^{\text {del }}$ conferred a dismal 6-year EFS of only 21\% [131].

$I K Z F 1^{\text {del }}$ is over-represented in high-risk subtypes (Table 1): $45 \%$ of $P h$ ALL, $60 \%$ Ph-like, and $88 \%$ of CRLF2. Even in the HRG group, IKZF1 ${ }^{\text {del }}$ conferred a further poorer outcome. For example, for Ph ALL patients, before the era of TKIs, IKZF1 ${ }^{\text {del }}$ conferred worse prognosis (4-year DFS of $55.5 \pm 9.5 \%$ for IKZF1 ${ }^{\text {del }}$ vs. $75.0 \pm 21.7 \%$ no-IKZF1 ${ }^{\text {del }}$ ) [135]. Ph-like ALL patients fared worse with additional IKZF1 ${ }^{\text {del }}$ (5-year EFS $48.6 \pm 7.0 \%$ vs. $71.7 \pm 8.0 \%$ ) [77], although another study found that presence of $I K Z F 1^{\text {del }}$ did not seem to confer a higher relapse risk [136].

For relapsed ALL, IKZF1 ${ }^{\text {del }}$ also confers an inferior outcome even after stem cell transplantation $[137,138]$. In the UKALL relapse protocols, patients with $I K Z F 1^{\text {del }}$ had a rather dismal 5-year OS of 30\% compared with 60\% for their IKZF1-neg counterparts [137,138].

Stanulla et al. showed that additional deletions of PAX5, CDKN2A/B, and PAR1 in addition to IKZFI $1^{\text {del }}$, which they defined as IKZF1 ${ }^{\text {plus }}$, conferred an even poorer outcome than IKZF1 ${ }^{\text {del }}$ alone, especially in MRD-IR and MRD-HR groups. In MS2003/2010, the prevalence of HRG increased dramatically in IKZF1 del and IKZF1 ${ }^{\text {plus }}$ compared with IKZF1-neg patients (Figure 6). Interestingly, a higher proportion of younger children have $I K Z F 1^{\text {plus }}\left(<10\right.$ years: $53.0 \%$ for IKZF1 $1^{\text {del }}$ vs. $61.9 \%$ for IKZF1 $\left.{ }^{\text {plus }}, p<0.001\right)$ [132]. 


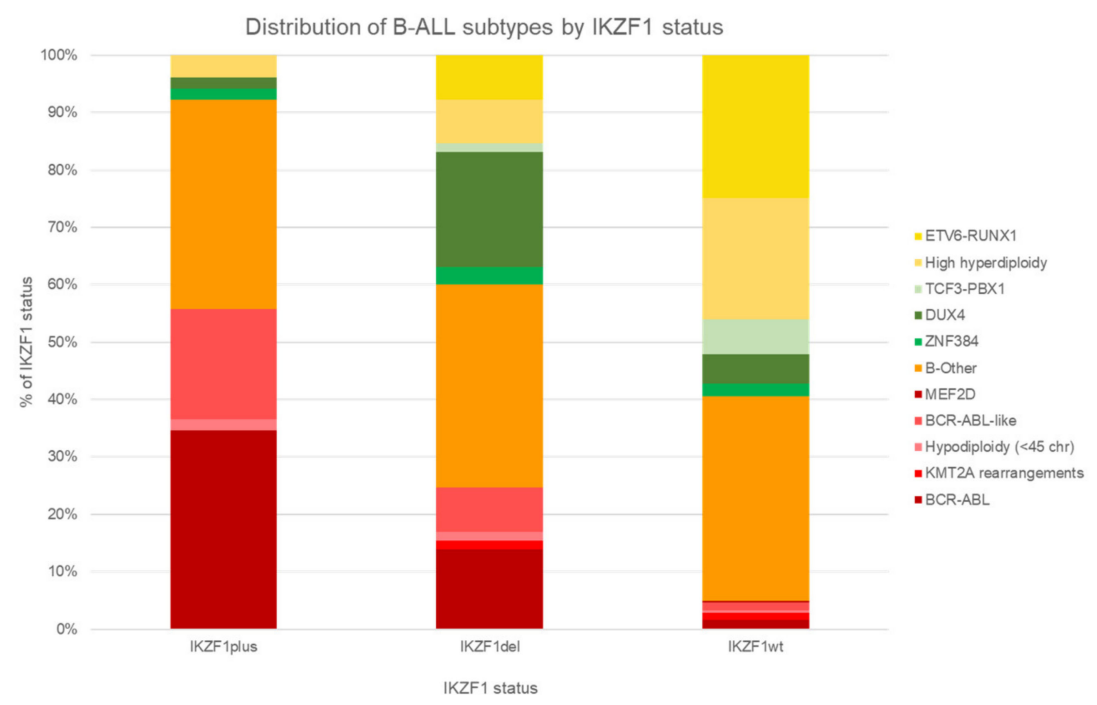

Figure 6. Distribution of subtypes co-occurring with $I K Z F 1^{\text {del }}$. The proportions of molecular subtypes co-occurring with IKZF1 $1^{\text {del }}$ and IKZF1 ${ }^{\text {plus }}$ are plotted and compared against subtypes with wild type IKZF1 (IKZF1-neg) for patients treated in the Malaysia-Singapore ALL trial group cohort. IKZF1 ${ }^{\text {plus }}$ has additional deletions of $P A X 5, C D K N 2 A / B$, or PAR1 in addition to $I K Z F 1^{d e l}$. Favorable-risk subtypes are in shades of yellow, intermediate-risk subtypes are in shades of green, and high-risk subtypes are in shades of red. B-others is depicted in orange. There is a greater proportion of high-risk subtypes co-occurring with IKZF1 $1^{d e l}$ and IKZF1 ${ }^{\text {plus }}$, in particular $B C R-A B L$, and a smaller proportion of low-risk subtypes $(p<0.001)$.

In MS2003, IKZF1 ${ }^{\text {del }}$ within the PAX5alt group conferred an extremely high risk of relapse (5-year CIR 80\%). These relapses in PAX5alt tend to be late (2-3 years from diagnosis) and extramedullary in nature (CNS/testicular). This adverse effect of co-deletion of IKZF1 del / PAX5alt seemed to be reversible with intensified therapy in MS2010 [9]. The presence of IKZF1 ${ }^{\text {del }}$ with PAX5alt may explain why PAX5alt patients in COG AALL0232 and adult ALL (ECOG/CALGB/SWOG) did poorly [3].

However, not all subgroups with $I K Z F 1^{\text {del }}$ require treatment intensification. Subgroup analyses by us and others have found that accompanying favorable cytogenetics, e.g., ETV6-RUNX1, high hyperdiploidy, and IRG with good outcome such as TCF3-PBX1, or $D U X 4 / E R G^{d e l}$, attenuates the negative impact of $I K Z F 1^{d e l}[9,63]$. IKZF1 ${ }^{\text {del }}$ occurs in $7 \%$ of ETV6-RUNX1, $6 \%$ of hyperdiploid, $3 \%$ of TCF3-PBX1, and $28 \%$ of DUX4. In these four genetic subtypes, IKZF1 del does not appear to affect clinical outcome. In patients with other subtypes who are EOI MRD-negative, IKZF1 ${ }^{\text {del }}$ also does not confer any adverse outcome. Taken together, $I K Z F 1^{\text {del }}$ conferred poorer outcome in three main groups: IRG (except TCF3-PBX1 and DUX4), HRG, and those who are EOI MRD-positive.

Mechanistically, the adverse molecular mechanisms of $I K Z F 1^{\text {del }}$ remain incompletely understood. IKZF1 ${ }^{\text {del }}$ is found to decrease differentiation and increase focal adhesion proteins that result in cell mislocalization in the extravascular niche [139]. Of interest, Churchman et al. demonstrated reversal of this phenomenon in IKZF1-aberrant BCR-ABL ALL by treatment with retinoid receptor agonists, thereby suggesting a possible therapeutic avenue for IKZF1 ${ }^{\text {del }}$ leukemias [140].

Recently, germline IKZF1 has also been characterized as a leukemia predisposition gene, where adverse germline IKZF1 variation has been found in familial pediatric ALL and occurs in approximately $1 \%$ of B-ALL patients [141].

\section{T-ALL}

Although T-cell ALL seems more genetically diverse than B-cell ALL [10,142,143], no recurrent genetic aberration in T-ALL confers a distinctly different prognostic outcome. The majority of genetic lesions in B-cell ALL and T-cell ALL are mutually exclusive. Only a 
few lesions can be found in both, namely $M L L$ and $B C R-A B L 1$ rearrangements [5]. T-ALL can be divided into biological subgroups either by transcription factor oncogenes or by dysregulated functional pathways [10,142]. The most commonly mutated amongst these various transcription factors include TAL1, TAL2, TLX1 (also known as HOX11), HOXA, LMO1, LMO2/LYL1, and NKX2-1 [5,10,142]. However, unlike B-ALL subtypes, no distinct T-ALL genetic alterations have been identified that are reproducibly associated with clinical outcomes. Therefore, for the purposes of this review, associations of T-ALL with clinical characteristics will not be addressed for every single genetic subtype, other than those with known relevance.

ETP ALL, or early T-cell precursor ALL, is a distinct form of leukemia characterized by reduced expression of T-cell markers (CD1a, CD8, and CD5) and aberrant expression of myeloid or stem-cell markers [144]. The gene expression profile of ETP-ALL is similar to that of hematopoietic stem cells, suggesting that ETP-ALL may lie closer along the spectrum of immature leukemias rather than true T-ALL, which is mature [4]. This immaturity of ETP-ALL mimics sensitivity to venetoclax in AML, also through BCL-2 dependence [145].

\subsection{T-ALL Interaction with Age and WBC}

Compared with patients with B-cell ALL, T-cell ALL patients are generally older, with a median presenting age of 9 years $[10,146]$. More than $50 \%$ of T-ALL also present with hyperleukocytosis, with a median count of $76 \times 10^{9} / \mathrm{L}[146,147]$. However unlike for B-ALL, the prognostic importance of age, presenting WBC, and NCI criteria in T-ALL is limited. Within T-ALL subtypes, SIL-TAL1 patients have no age preponderance, but had a higher WBC count at presentation (median 174,000/ $\mu$ L) [148]. Children with ETP ALL tended to have lower WBC at presentation, but there was generally no difference in age presentation compared with non-ETP T-ALL [149]. The clinical characteristics of most of the other T-ALL genetic subtypes are not well defined.

\subsection{T-ALL Interaction with MRD and Outcomes}

Compared with B-ALL, MRD kinetics in T-ALL is much slower. A large percentage of T-ALL patients have detectable EOI MRD. However, this high proportion of EOI MRD positivity in T-ALL is prognostically less significant compared with B-ALL. T-ALL outcomes remain favorable as long as they have low-level or undetectable EOC MRD [34,150]. Therefore, while a later MRD timepoint (i.e., consolidation) most effectively identifies HR T-ALL patients, the earlier end-induction timepoint is useful for identifying lower-risk patients who can receive de-intensified therapy $[74,151]$.

With contemporary therapy, T-ALL has achieved outcomes similar to that of B-ALL. Intensifying induction with dexamethasone, Protocol Ib in BFM, HDMTX, and Capizzi methotrexate-asparaginase during interim maintenance has improved the outcomes of patients [10]. Also historically associated with a poorer outcome, ETP-ALL now has similar survival to conventional T-ALL with modern risk-adapted therapy $[149,152]$. However, notably, relapsed T-ALL is notoriously difficult to salvage, especially because T-ALL becomes highly refractory to chemotherapy upon relapse [153-156]. Historical reinduction remission rates in relapsed T-ALL are estimated to be poor at 30\% to $40 \%$ [157].

Unlike B-ALL where there are various forms of effective immunotherapy, T-ALL has fewer effective options currently [157]. There is thus a need for a better way to treat relapsed or refractory cases. The involvement of JAK-STAT and PRC2 pathways in ETP-ALL suggests that $J A K$ inhibition and/or chromatin-modifying agents may be therapeutically useful. Despite promising preclinical studies inhibiting NOTCH signaling by g-secretase inhibitors, severe GI toxicities and lack of cytotoxic antitumor responses still limit their direct translation into patient benefit. More recently, preclinical studies have shown that dasatinib, an $A B L$-class inhibitor usually given for treatment of $B C R-A B L 1$ ALL, is surprisingly effective in a large proportion of pediatric T-ALL cases in vivo and in vitro, by which the drivers of drug sensitivity are LCK-dependent and ABL-independent [158]. 
In addition, venetoclax, a bcl2 inhibitor, when combined with chemotherapy may improve response and survival outcomes in T-ALL.

\section{Conclusions}

Exciting progress in genomic sequencing has greatly refined the genetic taxonomy of ALL. With these new genetic entities clinically characterized, each with its own unique prognostic and therapeutic vulnerability, we can refine ALL risk stratification beyond MRD and NCI criteria. Understanding the unique clinical characteristics underpinning each subtype can aid the clinician in the management of ALL. Further, a reliable and comprehensive molecular identification of ALL genetic aberrations, including the ability to detect rare subtypes, is critical for integrated risk-adapted therapy. Ultimately, identifying the complete constellation of genetic aberrations paves the way for potential therapeutic targeting and precision medicine in childhood ALL. Taken together, better and more accurate risk assignment will enable improved cures for ALL, with lesser side effects.

Author Contributions: S.H.R.L., Z.L., S.T.T., B.L.Z.O. and A.E.J.Y. contributed to writing, review, and editing. All authors have read and agreed to the published version of the manuscript.

Funding: S.H.R.L., B.L.Z.O. and A.E.J.Y. are funded by National Medical Research Council Singapore.

Conflicts of Interest: The authors declare no conflict of interest.

\section{References}

1. Pui, C.-H.; Nichols, K.E.; Yang, J.J. Somatic and germline genomics in paediatric acute lymphoblastic leukaemia. Nat. Rev. Clin. Oncol. 2019, 16, 227-240. [CrossRef]

2. Hunger, S.P.; Mullighan, C.G. Acute Lymphoblastic Leukemia in Children. N. Engl. J. Med. 2015, 373, 1541-1552. [CrossRef]

3. Gu, Z.; Churchman, M.L.; Roberts, K.G.; Moore, I.; Zhou, X.; Nakitandwe, J.; Hagiwara, K.; Pelletier, S.; Gingras, S.; Berns, H.; et al. PAX5-driven subtypes of B-progenitor acute lymphoblastic leukemia. Nat. Genet. 2019, 51, 296-307. [CrossRef] [PubMed]

4. Iacobucci, I.; Mullighan, C.G. Genetic Basis of Acute Lymphoblastic Leukemia. J. Clin. Oncol. 2017, 35, 975-983. [CrossRef] [PubMed]

5. Inaba, H.; Mullighan, C.G. Pediatric acute lymphoblastic leukemia. Haematologica 2020, 105, 2524-2539. [CrossRef] [PubMed]

6. Maloney, K.W.; Devidas, M.; Wang, C.; Mattano, L.A.; Friedmann, A.M.; Buckley, P.; Borowitz, M.J.; Carroll, A.J.; Gastier-Foster, J.M.; Heerema, N.A.; et al. Outcome in Children with Standard-Risk B-Cell Acute Lymphoblastic Leukemia: Results of Children's Oncology Group Trial AALL0331. J. Clin. Oncol. 2020, 38, 602-612. [CrossRef] [PubMed]

7. O'Connor, D.; Moorman, A.V.; Wade, R.; Hancock, J.; Tan, R.M.; Bartram, J.; Moppett, J.; Schwab, C.; Patrick, K.; Harrison, C.; et al. Use of Minimal Residual Disease Assessment to Redefine Induction Failure in Pediatric Acute Lymphoblastic Leukemia. J. Clin. Oncol. 2017, 35, 660-667. [CrossRef]

8. Yeoh, A.E.J.; Ariffin, H.; Chai, E.L.L.; Kwok, C.S.N.; Chan, Y.H.; Ponnudurai, K.; Campana, D.; Tan, P.L.; Chan, M.Y.; Kham, S.K.Y.; et al. Minimal residual disease-guided treatment deintensification for children with acute lymphoblastic leukemia: Results from the Malaysia-Singapore acute lymphoblastic leukemia 2003 Study. J. Clin. Oncol. 2012, 30, 2384-2392. [CrossRef] [PubMed]

9. Yeoh, A.E.J.; Lu, Y.; Ni Chin, W.H.; Chiew, E.K.H.; Lim, E.H.; Li, Z.; Kham, S.K.Y.; Chan, Y.H.; Abdullah, W.A.; Lin, H.P.; et al. Intensifying Treatment of Childhood B-Lymphoblastic Leukemia with IKZF1 Deletion Reduces Relapse and Improves Overall Survival: Results of Malaysia-Singapore ALL 2010 Study. J. Clin. Oncol. 2018, 36, 2726-2735. [CrossRef]

10. Teachey, D.T.; Pui, C.-H. Comparative features and outcomes between paediatric T-cell and B-cell acute lymphoblastic leukaemia. Lancet Oncol. 2019, 20, e142-e154. [CrossRef]

11. Ariffin, H.; Chen, S.P.; Kwok, C.S.; Quah, T.C.; Lin, H.P.; Yeoh, A.E.; Malaysia-Singapore Leukemia Study Group. Ethnic differences in the frequency of subtypes of childhood acute lymphoblastic leukemia: Results of the Malaysia-Singapore Leukemia Study Group. J. Pediatr. Hematol. Oncol. 2007, 29, 27-31. [CrossRef] [PubMed]

12. Liang, D.-C.; Shih, L.-Y.; Yang, C.-P.; Hung, I.-J.; Liu, H.-C.; Jaing, T.-H.; Yeh, T.-C.; Liang, S.-T.; Chang, C.-L.; Lee, E.-H.; et al. The Frequencies of ETV6-RUNX1 Fusion and Hyperdiploidy (>50 chromosomes) in Children with Acute Lymphoblastic Leukemia Are Lower in Far East than the West. Blood 2009, 114, 3064. [CrossRef]

13. Kager, L.; Lion, T.; Attarbaschi, A.; Koenig, M.; Strehl, S.; Haas, O.A.; Dworzak, M.N.; Schrappe, M.; Gadner, H.; Mann, G. Incidence and outcome of TCF3-PBX1-positive acute lymphoblastic leukemia in Austrian children. Haematologica 2007, 92, 1561-1564. [CrossRef]

14. Pui, C.-H.; Sandlund, J.T.; Pei, D.; Rivera, G.K.; Howard, S.C.; Ribeiro, R.C.; Rubnitz, J.E.; Razzouk, B.; Hudson, M.M.; Cheng, C.; et al. Results of therapy for acute lymphoblastic leukemia in black and white children. JAMA 2003, 290, 2001-2007. [CrossRef]

15. Kadan-Lottick, N.S. Survival Variability by Race and Ethnicity in Childhood Acute Lymphoblastic Leukemia. JAMA 2003, 290, 2008-2014. [CrossRef] [PubMed] 
16. Bhatia, S.; Sather, H.N.; Heerema, N.A.; Trigg, M.E.; Gaynon, P.S.; Robison, L.L. Racial and ethnic differences in survival of children with acute lymphoblastic leukemia. Blood 2002, 100, 1957-1964. [CrossRef] [PubMed]

17. Harvey, R.; Mullighan, C.G.; Chen, I.-M.; Wharton, W.; Mikhail, F.M.; Carroll, A.J.; Kang, H.; Liu, W.; Dobbin, K.K.; Smith, M.A.; et al. Rearrangement of CRLF2 is associated with mutation of JAK kinases, alteration of IKZF1, Hispanic/Latino ethnicity, and a poor outcome in pediatric B-progenitor acute lymphoblastic leukemia. Blood 2010, 115, 5312-5321. [CrossRef] [PubMed]

18. Medina-Sanson, A.; Núñez-Enríquez, J.C.; Hurtado-Cordova, E.; Pérez-Saldivar, M.L.; Martínez-García, A.; Jiménez-Hernández, E.; Fernández-López, J.C.; Martín-Trejo, J.A.; Pérez-Lorenzana, H.; Flores-Lujano, J.; et al. Genotype-Environment Interaction Analysis of NQO1, CYP2E1, and NAT2 Polymorphisms and the Risk of Childhood Acute Lymphoblastic Leukemia: A Report from the Mexican Interinstitutional Group for the Identification of the Causes of Childhood Leukemia. Front. Oncol. 2020, 10, 571869. [CrossRef]

19. Lee, S.H.R.; Qian, M.; Yang, W.; Diedrich, J.D.; Raetz, E.; Yang, W.; Dong, Q.; Devidas, M.; Pei, D.; Yeoh, A.; et al. Genome-Wide Association Study of Susceptibility Loci for TCF3-PBX1 Acute Lymphoblastic Leukemia in Children. J. Natl. Cancer Inst. 2021, 113, 933-937. [CrossRef]

20. Perez-Andreu, V.; Roberts, K.G.; Harvey, R.C.; Yang, W.; Cheng, C.; Pei, D.; Xu, H.; Gastier-Foster, J.; Shuyu, E.; Lim, J.Y.; et al. Inherited GATA3 variants are associated with Ph-like childhood acute lymphoblastic leukemia and risk of relapse. Nat. Genet. 2013, 45, 1494-1498. [CrossRef]

21. Smith, M.; Arthur, D.; Camitta, B.; Carroll, A.J.; Crist, W.; Gaynon, P.; Gelber, R.; Heerema, N.; Korn, E.L.; Link, M.; et al. Uniform approach to risk classification and treatment assignment for children with acute lymphoblastic leukemia. J. Clin. Oncol. 1996, 14, 18-24. [CrossRef] [PubMed]

22. Pieters, R.; Schrappe, M.; De Lorenzo, P.; Hann, I.; De Rossi, G.; Felice, M.; Hovi, L.; LeBlanc, T.; Szczepanski, T.; Ferster, A.; et al. A treatment protocol for infants younger than 1 year with acute lymphoblastic leukaemia (Interfant-99): An observational study and a multicentre randomised trial. Lancet 2007, 370, 240-250. [CrossRef]

23. Pieters, R.; De Lorenzo, P.; Ancliffe, P.; Aversa, L.A.; Brethon, B.; Biondi, A.; Campbell, M.; Escherich, G.; Ferster, A.; Gardner, R.A.; et al. Outcome of Infants Younger Than 1 Year with Acute Lymphoblastic Leukemia Treated with the Interfant-06 Protocol: Results from an International Phase III Randomized Study. J. Clin. Oncol. 2019, 37, 2246-2256. [CrossRef] [PubMed]

24. Andersson, A.K.; Ma, J.; Wang, J.; Chen, X.; Gedman, A.L.; Dang, J.; Nakitandwe, J.; Holmfeldt, L.; Parker, M.; Easton, J.; et al. The landscape of somatic mutations in infant MLL-rearranged acute lymphoblastic leukemias. Nat. Genet. 2015, 47, 330-337. [CrossRef] [PubMed]

25. Winters, A.C.; Bernt, K.M. MLL-Rearranged Leukemias-An Update on Science and Clinical Approaches. Front. Pediatr. 2017, 5, 4. [CrossRef]

26. Britten, O.; Ragusa, D.; Tosi, S.; Mostafa Kamel, Y. MLL-Rearranged Acute Leukemia with t(4;11)(q21;q23)-Current Treatment Options. Is There a Role for CAR-T Cell Therapy? Cells 2019, 8, 1341. [CrossRef] [PubMed]

27. Reaman, G.H.; Sposto, R.; Sensel, M.G.; Lange, B.J.; Feusner, J.H.; Heerema, N.A.; Leonard, M.; Holmes, E.J.; Sather, H.N.; Pendergrass, T.W.; et al. Treatment outcome and prognostic factors for infants with acute lymphoblastic leukemia treated on two consecutive trials of the Children's Cancer Group. J. Clin. Oncol. 1999, 17, 445-455. [CrossRef]

28. Van der Linden, M.H.; Valsecchi, M.G.; De Lorenzo, P.; Möricke, A.; Janka, G.; Leblanc, T.M.; Felice, M.; Biondi, A.; Campbell, M.; Hann, I.; et al. Outcome of congenital acute lymphoblastic leukemia treated on the Interfant-99 protocol. Blood 2009, 114, 3764-3768. [CrossRef]

29. Van Dongen, J.J.; Seriu, T.; Panzer-Grümayer, E.R.; Biondi, A.; Pongers-Willemse, M.J.; Corral, L.; Stolz, F.; Schrappe, M.; Masera, G.; Kamps, W.A.; et al. Prognostic value of minimal residual disease in acute lymphoblastic leukaemia in childhood. Lancet 1998, 352, 1731-1738. [CrossRef]

30. Della Starza, I.; Chiaretti, S.; De Propris, M.S.; Elia, L.; Cavalli, M.; DE Novi, L.A.; Soscia, R.; Messina, M.; Vitale, A.; Guarini, A.; et al. Minimal Residual Disease in Acute Lymphoblastic Leukemia: Technical and Clinical Advances. Front. Oncol. 2019, 9, 726. [CrossRef]

31. Eckert, C.; Flohr, T.; Koehler, R.; Hagedorn, N.; Moericke, A.; Stanulla, M.; Kirschner-Schwabe, R.; Cario, G.; Stackelberg, A.; Bartram, C.R.; et al. Very early/early relapses of acute lymphoblastic leukemia show unexpected changes of clonal markers and high hetero-geneity in response to initial and relapse treatment. Leukemia 2011, 25, 1305-1313. [CrossRef]

32. Kotrová, M.; Muzikova, K.; Mejstrikova, E.; Novakova, M.; Bakardjieva-Mihaylova, V.; Fišer, K.; Stuchly, J.; Giraud, M.; Salson, M.; Pott, C.; et al. The predictive strength of next-generation sequencing MRD detection for relapse compared with current methods in childhood ALL. Blood 2015, 126, 1045-1047. [CrossRef]

33. O'Connor, D.; Enshaei, A.; Bartram, J.; Hancock, J.; Harrison, C.J.; Hough, R.; Samarasinghe, S.; Schwab, C.; Vora, A.; Wade, R.; et al. Genotype-Specific Minimal Residual Disease Interpretation Improves Stratification in Pediatric Acute Lymphoblastic Leukemia. J. Clin. Oncol. 2018, 36, 34-43. [CrossRef]

34. Pui, C.H.; Pei, D.; Raimondi, S.C.; Coustan-Smith, E.; Jeha, S.; Cheng, C.; Bowman, W.P.; Sandlund, J.T.; Ribeiro, R.C.; Rubnitz, J.E.; et al. Clinical impact of minimal residual disease in children with different subtypes of acute lymphoblastic leukemia treated with Response-Adapted therapy. Leukemia 2017, 31, 333-339. [CrossRef] [PubMed]

35. Borowitz, M.J.; Devidas, M.; Hunger, S.P.; Bowman, W.P.; Carroll, A.J.; Carroll, W.L.; Linda, S.; Martin, P.L.; Pullen, D.J.; Viswanatha, D.; et al. Clinical significance of minimal residual disease in childhood acute lymphoblastic leukemia and its relationship to other prognostic factors: A Children's Oncology Group study. Blood 2008, 111, 5477-5485. [CrossRef] [PubMed] 
36. Borowitz, M.J.; Wood, B.L.; Devidas, M.; Loh, M.L.; Raetz, E.A.; Salzer, W.L.; Nachman, J.B.; Carroll, A.J.; Heerema, N.A.; Gastier-Foster, J.M.; et al. Prognostic significance of minimal residual disease in high risk B-ALL: A report from Children's Oncology Group study AALL0232. Blood 2015, 126, 964-971. [CrossRef]

37. Pieters, R.; de Groot-Kruseman, H.; Van der Velden, V.; Fiocco, M.; Berg, H.V.D.; de Bont, E.; Egeler, R.M.; Hoogerbrugge, P.; Kaspers, G.; Van der Schoot, E.; et al. Successful Therapy Reduction and Intensification for Childhood Acute Lymphoblastic Leukemia Based on Minimal Residual Disease Monitoring: Study ALL10 From the Dutch Childhood Oncology Group. J. Clin. Oncol. 2016, 34, 2591-2601. [CrossRef] [PubMed]

38. Bhojwani, D.; Pei, D.; Sandlund, J.T.; Jeha, S.; Ribeiro, R.C.; Rubnitz, J.E.; Raimondi, S.C.; Shurtleff, S.; Onciu, M.; Cheng, C.; et al. ETV6-RUNX1-positive childhood acute lymphoblastic leukemia: Improved outcome with contemporary therapy. Leukemia 2012, 26, 265-270. [CrossRef]

39. Burmeister, T.; Gökbuget, N.; Schwartz, S.; Fischer, L.; Hubert, D.; Sindram, A.; Hoelzer, D.; Thiel, E. Clinical features and prognostic implications of TCF3-PBX1 and ETV6-RUNX1 in adult acute lymphoblastic leu-kemia. Haematologica 2010, 95, 241-246. [CrossRef]

40. Asai, D.; Imamura, T.; Yamashita, Y.; Suenobu, S.; Moriya-Saito, A.; Hasegawa, D.; Deguchi, T.; Hashii, Y.; Endo, M.; Hatakeyama, N.; et al. Outcome of TCF3-PBX1 positive pediatric acute lymphoblastic leukemia patients in J apan: A collaborative study of Japan Association of Childhood Leukemia Study (JACLS) and Children's Cancer and Leukemia Study Group (CCLSG). Cancer Med. 2014, 3, 623-631. [CrossRef]

41. Kager, L.; Lion, T.; Attarbaschi, A.; Koenig, M.; Strehl, S.; Haas, O.A.; Dworzak, M.N.; Schrappe, M.; Gadner, H.; Mann, G. Treatment Response and Outcome in Childhood t(1;19)/TCF3-PBX1 Positive Acute Lymphoblastic Leukemia: A Report from the Austrian BFM Group. Blood 2005, 106, 1458. [CrossRef]

42. Crist, W.M.; Carroll, A.J.; Shuster, J.J.; Behm, F.G.; Whitehead, M.; Vietti, T.J.; Look, A.T.; Mahoney, D.; Ragab, A.; Pullen, D.J. Poor prognosis of children with pre-B acute lymphoblastic leukemia is associated with the $t(1 ; 19)(q 23 ; p 13)$ : A Pediatric Oncology Group study. Blood 1990, 76, 117-122. [CrossRef] [PubMed]

43. Lin, A.; Cheng, F.W.; Chiang, A.K.; Luk, C.-W.; Li, R.C.; Ling, A.S.; Cheuk, D.K.; Chang, K.-O.; Ku, D.; Lee, V.; et al. Excellent outcome of acute lymphoblastic leukaemia withTCF3-PBX1rearrangement in Hong Kong. Pediatr. Blood Cancer 2018, 65, e27346. [CrossRef] [PubMed]

44. Borowitz, M.J.; Pullen, D.J.; Shuster, J.J.; Viswanatha, D.; Montgomery, K.; Willman, C.L.; Camitta, B. Minimal residual disease detection in childhood precursor-B-cell acute lymphoblastic leukemia: Relation to other risk factors. A Children's Oncology Group study. Leukemia 2003, 17, 1566-1572. [CrossRef] [PubMed]

45. Xue, Y.-J.; Wang, Y.; Jia, Y.-P.; Zuo, Y.-X.; Wu, J.; Lu, A.-D.; Zhang, L.-P. The role of minimal residual disease in specific subtypes of pediatric acute lymphoblastic leukemia. Int. J. Hematol. 2021, 113, 547-555. [CrossRef]

46. Pui, C.-H.; Campana, D.; Pei, D.; Bowman, W.P.; Sandlund, J.T.; Kaste, S.C.; Ribeiro, R.C.; Rubnitz, J.E.; Raimondi, S.C.; Onciu, M.; et al. Treating childhood acute lymphoblastic leukemia without cranial irradiation. N. Engl. J. Med. 2009, 360, $2730-2741$. [CrossRef]

47. Jeha, S.; Pei, D.; Choi, J.; Cheng, C.; Sandlund, J.T.; Coustan-Smith, E.; Campana, D.; Inaba, H.; Rubnitz, J.E.; Ribeiro, R.C.; et al. Improved CNS Control of Childhood Acute Lymphoblastic Leukemia Without Cranial Irradiation: St Jude Total Therapy Study 16. J. Clin. Oncol. 2019, 37, 3377-3391. [CrossRef] [PubMed]

48. Hirabayashi, S.; Butler, E.; Ohki, K.; Kiyokawa, N.; Bergmann, A.K.; Boer, J.M.; Cavé, H.; Cazzaniga, G.; Yeoh, A.E.J.; Imamura, T.; et al. Acute Lymphoblastic Leukemia with Zinc-Finger Protein 384 (ZNF384)-Related Rearrangements: A Retrospective Analysis from the Ponte Di Legno Childhood ALL Working Group. Blood 2019, 134 (Suppl. 1), 652. [CrossRef]

49. McClure, B.J.; Heatley, S.L.; Kok, C.H.; Sadras, T.; An, J.; Hughes, T.P.; Lock, R.B.; Yeung, D.; Sutton, R.; White, D.L. Pre-B acute lymphoblastic leukaemia recurrent fusion, EP300-ZNF384, is associated with a distinct gene expression. Br. J. Cancer 2018, 118, 1000-1004. [CrossRef]

50. Shinsuke, H.; Kentaro, O.; Kazuhiko, N.; Hitoshi, I.; Yukihide, M.; Kohji, O.; Akinori, Y.; Kazuki, T.; Yuya, S.; Ai, Y.; et al. ZNF384-related fusion genes define a subgroup of childhood B-cell precursor acute lymphoblastic leukemia with a characteristic immunotype. Haematologica 2017, 102, 118-129. [CrossRef]

51. Hirabayashi, S.; Butler, E.R.; Ohki, K.; Kiyokawa, N.; Bergmann, A.K.; Möricke, A.; Boer, J.M.; Cavé, H.; Cazzaniga, G.; Yeoh, A.E.J.; et al. Clinical characteristics and outcomes of B-ALL with ZNF384 rearrangements: A retrospective analysis by the Ponte di Legno Childhood ALL Working Group. Leukemia 2021. [CrossRef]

52. Nishimura, A.; Hasegawa, D.; Hirabayashi, S.; Kanabuchi, S.; Yamamoto, K.; Aiga, S.; Nishitani, M.; Hosoya, Y.; Noguchi, Y.; Ohki, K.; et al. Very late relapse cases of TCF3-ZNF384-positive acute lymphoblastic leukemia. Pediatric Blood Cancer 2019, 66, e27891. [CrossRef] [PubMed]

53. Stasevich, I.; Inglott, S.; Austin, N.; Chatters, S.; Chalker, J.; Addy, D.; Dryden, C.; Ancliff, P.; Ford, A.; Williams, O.; et al. PAX5 alterations in genetically unclassified childhood Precursor B-cell acute lymphoblastic leukaemia. Br. J. Haematol. 2015, 171, 263-272. [CrossRef] [PubMed]

54. Bastian, L.; Schroeder, M.P.; Eckert, C.; Schlee, C.; Tanchez, J.O.; Kämpf, S.; Wagner, D.L.; Schulze, V.; Isaakidis, K.; Lázaro-Navarro, J.; et al. PAX5 biallelic genomic alterations define a novel subgroup of B-cell precursor acute lymphoblastic leukemia. Leukemia 2019, 33, 1895-1909. [CrossRef] 
55. Lilljebjörn, H.; Henningsson, R.; Hyrenius-Wittsten, A.; Olsson, L.; Orsmark-Pietras, C.; Von Palffy, S.; Askmyr, M.; Rissler, M.; Schrappe, M.; Cario, G.; et al. Identification of ETV6-RUNX1-like and DUX4-rearranged subtypes in paediatric B-cell precursor acute lympho-blastic leukaemia. Nat. Commun. 2016, 7, 11790. [CrossRef]

56. Zaliova, M.; Kotrova, M.; Bresolin, S.; Stuchly, J.; Stary, J.; Hrusak, O.; Te Kronnie, G.; Trka, J.; Zuna, J.; Vaskova, M. ETV6/RUNX1like acute lymphoblastic leukemia: A novel B-cell precursor leukemia subtype associated with the CD27/CD44 immunophenotype. Genes Chromosomes Cancer 2017, 56, 608-616. [CrossRef]

57. Jeha, S.; Choi, J.; Roberts, K.G.; Pei, D.; Coustan-Smith, E.; Inaba, H.; Rubnitz, J.E.; Ribeiro, R.C.; Gruber, T.A.; Raimondi, S.C.; et al. Clinical significance of novel subtypes of acute lymphoblastic leukemia in the context of minimal residual disease-directed therapy. Blood Cancer Discov. 2021, 2, 326-337. [CrossRef] [PubMed]

58. Zhang, J.; McCastlain, K.; Yoshihara, H.; Xu, B.; Chang, Y.; Churchman, M.L.; Wu, G.; Li, Y.; Wei, L.; Iacobucci, I.; et al. Deregulation of DUX4 and ERG in acute lymphoblastic leukemia. Nat. Genet. 2016, 48, 1481-1489. [CrossRef] [PubMed]

59. Schinnerl, D.; Mejstrikova, E.; Schumich, A.; Zaliova, M.; Fortschegger, K.; Nebral, K.; Attarbaschi, A.; Fiser, K.; Kauer, M.O.; Popitsch, N.; et al. CD371 cell surface expression: A unique feature of DUX4-rearranged acute lymphoblastic leukemia. Haematologica 2019, 104, e352-e355. [CrossRef] [PubMed]

60. Rehn, J.A.; O'Connor, M.J.; White, D.L.; Yeung, D.T. DUX Hunting-Clinical Features and Diagnostic Challenges Associated with DUX4-Rearranged Leukaemia. Cancers 2020, 12, 2815. [CrossRef]

61. Marincevic-Zuniga, Y.; Dahlberg, J.; Nilsson, S.; Raine, A.; Nystedt, S.; Lindqvist, C.M.; Berglund, E.C.; Abrahamsson, J.; Cavelier, L.; Forestier, E.; et al. Transcriptome sequencing in pediatric acute lymphoblastic leukemia identifies fusion genes associated with distinct DNA methylation profiles. J. Hematol. Oncol. 2017, 10, 148. [CrossRef]

62. Clappier, E.; Auclerc, M.-F.; Rapion, J.; Bakkus, M.; Caye, A.; Khemiri, A.; Giroux, C.; Hernandez, L.; Kabongo, E.; Savola, S.; et al. An intragenic ERG deletion is a marker of an oncogenic subtype of B-cell precursor acute lymphoblastic leukemia with a favorable outcome despite frequent IKZF1 deletions. Leukemia 2014, 28, 70-77. [CrossRef]

63. Zaliova, M.; Zimmermannova, O.; Dörge, P.; Eckert, C.; Möricke, A.; Zimmermann, M.; Stuchly, J.; Teigler-Schlegel, A.; Meissner, B.; Koehler, R.; et al. ERG deletion is associated with CD2 and attenuates the negative impact of IKZF1 deletion in childhood acute lym-phoblastic leukemia. Leukemia 2014, 28, 182-185. [CrossRef]

64. Vendramini, E.; Giordan, M.; Giarin, E.; Michielotto, B.; Fazio, G.; Cazzaniga, G.; Biondi, A.; Silvestri, D.; Valsecchi, M.G.; Muckenthaler, M.; et al. High expression of miR-125b-2 and SNORD116 noncoding RNA clusters characterize ERG-related B cell precursor acute lymphoblastic leukemia. Oncotarget 2017, 8, 42398-42413. [CrossRef]

65. Zaliova, M.; Stuchly, J.; Winkowska, L.; Musilova, A.; Fiser, K.; Slamova, M.; Starkova, J.; Vaskova, M.; Hrusak, O.; Sramkova, L.; et al. Genomic landscape of pediatric B-other acute lymphoblastic leukemia in a consecutive European cohort. Haematologica 2019, 104, 1396-1406. [CrossRef] [PubMed]

66. Novakova, M.; Zaliova, M.; Fiser, K.; Vakrmanova, B.; Slamova, L.; Musilova, A.; Brüggemann, M.; Ritgen, M.; Fronkova, E.; Kalina, T; et al. DUX4r, ZNF384r and PAX5-P80R mutated B-cell precursor acute lymphoblastic leukemia frequently undergo monocytic switch. Haematologica 2020, 106, 2066-2075. [CrossRef]

67. Zaliova, M.; Potuckova, E.; Hovorkova, L.; Musilova, A.; Winkowska, L.; Fiser, K.; Stuchly, J.; Mejstrikova, E.; Starkova, J.; Zuna, J.; et al. ERG deletions in childhood acute lymphoblastic leukemia with DUX4 rearrangements are mostly polyclonal, prognostically relevant and their detection rate strongly depends on screening method sensitivity. Haematologica 2019, 104, 1407-1416. [CrossRef] [PubMed]

68. Schrappe, M.; Hunger, S.P.; Pui, C.-H.; Saha, V.; Gaynon, P.S.; Baruchel, A.; Conter, V.; Otten, J.; Ohara, A.; Versluys, A.B.; et al. Outcomes after induction failure in childhood acute lymphoblastic leukemia. N. Engl. J. Med. 2012, 366, 1371-1381. [CrossRef] [PubMed]

69. Aricò, M.; Schrappe, M.; Hunger, S.P.; Carroll, W.L.; Conter, V.; Galimberti, S.; Manabe, A.; Saha, V.; Baruchel, A.; Vettenranta K.; et al. Clinical outcome of children with newly diagnosed philadelphia chromosome-positive acute lymphoblastic leukemia treated between 1995 and 2005. J. Clin. Oncol. 2010, 28, 4755-4761. [CrossRef]

70. Biondi, A.; Schrappe, M.; De Lorenzo, P.; Castor, A.; Lucchini, G.; Gandemer, V.; Pieters, R.; Stary, J.; Escherich, G.; Campbell, M.; et al. Imatinib after induction for treatment of children and adolescents with Philadelphia-chromosome-positive acute lym-phoblastic leukaemia (EsPhALL): A randomised, open-label, intergroup study. Lancet Oncol. 2012, 13, 936-945. [CrossRef]

71. Schultz, K.R.; Bowman, W.P.; Aledo, A.; Slayton, W.B.; Sather, H.; Devidas, M.; Wang, C.; Davies, S.M.; Gaynon, P.S.; Trigg, M.; et al. Improved early event-free survival with imatinib in philadelphia chromosome-positive acute lymphoblastic leukemia: A children's oncology group study. J. Clin. Oncol. 2009, 27, 5175-5181. [CrossRef]

72. Shen, S.; Chen, X.; Cai, J.; Yu, J.; Gao, J.; Hu, S.; Zhai, X.; Liang, C.; Ju, X.; Jiang, H.; et al. Effect of Dasatinib vs Imatinib in the Treatment of Pediatric Philadelphia Chromosome-Positive Acute Lymphoblastic Leukemia: A Randomized Clinical Trial. JAMA Oncol. 2020, 6, 358-366. [CrossRef]

73. Vora, A.; Goulden, N.; Wade, R.; Mitchell, C.; Hancock, J.; Hough, R.; Rowntree, C.; Richards, S. Treatment reduction for children and young adults with low-risk acute lymphoblastic leukaemia defined by minimal residual disease (UKALL 2003): A randomised controlled trial. Lancet Oncol. 2013, 14, 199-209. [CrossRef] 
74. Vora, A.; Goulden, N.; Mitchell, C.; Hancock, J.; Hough, R.; Rowntree, C.; Moorman, A.; Wade, R. Augmented post-remission therapy for a minimal residual disease-defined high-risk subgroup of children and young people with clinical standard-risk and intermediate-risk acute lymphoblastic leukaemia (UKALL 2003): A randomised controlled trial. Lancet Oncol. 2014, 15, 809-818. [CrossRef]

75. Conter, V.; Bartram, C.R.; Valsecchi, M.G.; Schrauder, A.; Panzer-Grümayer, R.; Möricke, A.; Aricò, M.; Zimmermann, M.; Mann, G.; De Rossi, G.; et al. Molecular response to treatment redefines all prognostic factors in children and adolescents with B-cell precursor acute lymphoblastic leukemia: Results in 3184 patients of the AIEOP-BFM ALL 2000 study. Blood 2010, 115, 3206-3214. [CrossRef] [PubMed]

76. Den Boer, M.L.; van Slegtenhorst, M.; De Menezes, R.X.; Cheok, M.H.; Buijs-Gladdines, J.G.; Peters, S.T.; Van Zutven, L.J.; Beverloo, H.B.; Van der Spek, P.J.; Escherich, G.; et al. A subtype of childhood acute lymphoblastic leukaemia with poor treatment outcome: A genome-wide classification study. Lancet Oncol. 2009, 10, 125-134. [CrossRef]

77. Roberts, K.G.; Li, Y.; Payne-Turner, D.; Harvey, R.C.; Yang, Y.-L.; Pei, D.; McCastlain, K.; Ding, L.; Lu, C.; Song, G.; et al. Targetable Kinase-Activating Lesions in Ph-like Acute Lymphoblastic Leukemia. N. Engl. J. Med. 2014, 371, 1005-1015. [CrossRef]

78. Slayton, W.B.; Schultz, K.R.; Kairalla, J.A.; Devidas, M.; Mi, X.; Pulsipher, M.A.; Chang, B.H.; Mullighan, C.; Iacobucci, I.; Silverman, L.B.; et al. Dasatinib Plus Intensive Chemotherapy in Children, Adolescents, and Young Adults with Philadelphia Chromo-some-Positive Acute Lymphoblastic Leukemia: Results of Children's Oncology Group Trial AALL0622. J. Clin. Oncol. 2018, 36, 2306-2314. [CrossRef]

79. Schlieben, S.; Borkhardt, A.; Reinisch, I.; Ritterbach, J.; Janssen, J.W.; Ratei, R.; Schrappe, M.; Repp, R.; Zimmermann, M.; Kabisch, $\mathrm{H}$; ; et al. Incidence and clinical outcome of children with BCR/ABL-positive acute lymphoblastic leukemia (ALL). A prospective RT-PCR study based on 673 patients enrolled in the German pediatric multicenter therapy trials ALL-BFM-90 and CoALL-05-92. Leukemia 1996, 10, 957-963.

80. Tasian, S.K.; Loh, M.L.; Hunger, S.P. Philadelphia chromosome-like acute lymphoblastic leukemia. Blood 2017, 130, 2064-2072. [CrossRef] [PubMed]

81. Roberts, K.G.; Pei, D.; Campana, D.; Payne-Turner, D.; Li, Y.; Cheng, C.; Sandlund, J.T.; Jeha, S.; Easton, J.; Becksfort, J.; et al. Outcomes of children with BCR-ABL1-like acute lymphoblastic leukemia treated with risk-directed therapy based on the levels of minimal residual disease. J. Clin. Oncol. 2014, 32, 3012-3020. [CrossRef]

82. Roberts, K.G. Genetics and prognosis of ALL in children vs adults. Hematol. Am. Soc. Hematol. Educ. Program. 2018, 2018, 137-145. [CrossRef]

83. Palmi, C.; Vendramini, E.; Silvestri, D.; Longinotti, G.; Frison, D.; Cario, G.; Shochat, C.; Stanulla, M.; Rossi, V.; Di Meglio, A.M.; et al. Poor prognosis for P2RY8-CRLF2 fusion but not for CRLF2 over-expression in children with intermediate risk B-cell precursor acute lymphoblastic leukemia. Leukemia 2012, 26, 2245-2253. [CrossRef]

84. Reshmi, S.C.; Harvey, R.C.; Roberts, K.G.; Stonerock, E.; Smith, A.; Jenkins, H.; Chen, I.-M.; Valentine, M.; Liu, Y.; Li, Y.; et al. Targetable kinase gene fusions in high-risk B-ALL: A study from the Children's Oncology Group. Blood 2017, 129, 3352-3361. [CrossRef] [PubMed]

85. Tasian, S.K.; Loh, M.L. Understanding the Biology of CRLF2-Overexpressing Acute Lymphoblastic Leukemia. Crit. Rev. Oncog. 2011, 16, 13-24. [CrossRef]

86. Yoda, A.; Yoda, Y.; Chiaretti, S.; Bar-Natan, M.; Mani, K.; Rodig, S.J.; West, N.; Xiao, Y.; Brown, J.R.; Mitsiades, C.; et al. Functional screening identifies CRLF2 in precursor B-cell acute lymphoblastic leukemia. Proc. Natl. Acad. Sci. USA 2010, 107, $252-257$. [CrossRef] [PubMed]

87. Mullighan, C.G.; Collins-Underwood, J.R.; Phillips, L.A.; Loudin, M.G.; Liu, W.; Zhang, J.; Ma, J.; Coustan-Smith, E.; Harvey, R.C.; Willman, C.L.; et al. Rearrangement of CRLF2 in B-progenitor- and Down syndrome-associated acute lymphoblastic leukemia. Nat. Genet. 2009, 41, 1243-1246. [CrossRef]

88. Russell, L.; Capasso, M.; Vater, I.; Akasaka, T.; Bernard, O.; Calasanz, M.J.; Chandrasekaran, T.; Chapiro, E.; Gesk, S.; Griffiths, M.; et al. Deregulated expression of cytokine receptor gene, CRLF2, is involved in lymphoid transformation in B-cell precursor acute lymphoblastic leukemia. Blood 2009, 114, 2688-2698. [CrossRef] [PubMed]

89. Ensor, H.M.; Schwab, C.; Russell, L.; Richards, S.M.; Morrison, H.; Masic, D.; Jones, L.; Kinsey, S.E.; Vora, A.J.; Mitchell, C.D.; et al. Demographic, clinical, and outcome features of children with acute lymphoblastic leukemia and CRLF2 deregulation: Results from the MRC ALL97 clinical trial. Blood 2011, 117, 2129-2136. [CrossRef] [PubMed]

90. Liu, Y.-F.; Wang, B.-Y.; Zhang, W.-N.; Huang, J.-Y.; Li, B.-S.; Zhang, M.; Jiang, L.; Li, J.-F.; Wang, M.-J.; Dai, Y.-J.; et al. Genomic Profiling of Adult and Pediatric B-cell Acute Lymphoblastic Leukemia. EBioMedicine 2016, 8, 173-183. [CrossRef] [PubMed]

91. Gu, Z.; Churchman, M.; Roberts, K.; Li, Y.; Liu, Y.; Harvey, R.C.; McCastlain, K.; Reshmi, S.C.; Payne-Turner, D.; Iacobucci, I.; et al. Genomic analyses identify recurrent MEF2D fusions in acute lymphoblastic leukaemia. Nat. Commun. 2016, 7, 13331. [CrossRef] [PubMed]

92. Ohki, K.; Kiyokawa, N.; Saito, Y.; Hirabayashi, S.; Nakabayashi, K.; Ichikawa, H.; Momozawa, Y.; Okamura, K.; Yoshimi, A.; Ogata-Kawata, H.; et al. Clinical and molecular characteristics of MEF2D fusion-positive B-cell precursor acute lymphoblastic leukemia in childhood, including a novel translocation resulting in MEF2D-HNRNPH1 gene fusion. Haematologica 2019, 104, 128-137. [CrossRef] 
93. Suzuki, K.; Okuno, Y.; Kawashima, N.; Muramatsu, H.; Okuno, T.; Wang, X.; Kataoka, S.; Sekiya, Y.; Hamada, M.; Murakami, N.; et al. MEF2D-BCL9 Fusion Gene Is Associated with High-Risk Acute B-Cell Precursor Lymphoblastic Leukemia in Ado-lescents. J. Clin. Oncol. 2016, 34, 3451-3459. [CrossRef]

94. Zhang, C.; Richon, V.; Ni, X.; Talpur, R.; Duvic, M. Selective induction of apoptosis by histone deacetylase inhibitor SAHA in cutaneous T-cell lymphoma cells: Relevance to mechanism of therapeutic action. J. Investig. Dermatol. 2005, 125, 1045-1052. [CrossRef]

95. Stutterheim, J.; van der Sluis, I.M.; De Lorenzo, P.; Alten, J.; Ancliff, P.; Attarbaschi, A.; Brethon, B.; Biondi, A.; Campbell, M.; Cazzaniga, G.; et al. Clinical Implications of Minimal Residual Disease Detection in Infants with KMT2A-Rearranged Acute Lymphoblastic Leukemia Treated on the Interfant-06 Protocol. Blood 2020, 136, 41-42. [CrossRef]

96. Hilden, J.M.; Dinndorf, P.A.; Meerbaum, S.O.; Sather, H.; Villaluna, D.; Heerema, N.A.; McGlennen, R.; Smith, F.O.; Woods, W.G.; Salzer, W.L.; et al. Analysis of prognostic factors of acute lymphoblastic leukemia in infants: Report on CCG 1953 from the Children's Oncology Group. Blood 2006, 108, 441-451. [CrossRef]

97. Woerden, N.L.R.-V.; Beverloo, H.B.; Veerman, A.J.P.; Camitta, B.M.; Loonen, A.H.; Van Wering, E.R.; Slater, R.M.; Harbott, J.; Boer, M.L.D.; Ludwig, W.D.; et al. In vitro drug-resistance profile in infant acute lymphoblastic leukemia in relation to age, MLL rearrangements and immunophenotype. Leukemia 2004, 18, 521-529. [CrossRef] [PubMed]

98. Mann, G.; Attarbaschi, A.; Schrappe, M.; De Lorenzo, P.; Peters, C.; Hann, I.; De Rossi, G.; Felice, M.; Lausen, B.; Leblanc, T.; et al. Improved outcome with hematopoietic stem cell transplantation in a poor prognostic subgroup of infants with mixed-lineageleukemia (MLL)-rearranged acute lymphoblastic leukemia: Results from the Interfant-99 Study. Blood 2010, 116, 2644-2650. [CrossRef] [PubMed]

99. Dreyer, Z.E.; Dinndorf, P.A.; Camitta, B.; Sather, H.; La, M.K.; Devidas, M.; Hilden, J.M.; Heerema, N.A.; Sanders, J.E.; McGlennen, R.; et al. Analysis of the role of hematopoietic stem-cell transplantation in infants with acute lymphoblastic leukemia in first remission and MLL gene rearrangements: A report from the Children's Oncology Group. J. Clin. Oncol. 2011, $29,214-222$. [CrossRef] [PubMed]

100. Pui, C.-H.; Gaynon, P.S.; Boyett, J.M.; Chessells, J.M.; Baruchel, A.; Kamps, W.; Silverman, L.B.; Biondi, A.; Harms, D.O.; Vilmer, E.; et al. Outcome of treatment in childhood acute lymphoblastic leukaemia with rearrangements of the 11q23 chromosomal region. Lancet 2002, 359, 1909-1915. [CrossRef]

101. Pui, C.-H.; Chessells, J.M.; Camitta, B.M.; Baruchel, A.; Biondi, A.; Boyett, J.M.; Carroll, A.J.; Eden, O.B.; Evans, W.E.; Gadner, H.; et al. Clinical heterogeneity in childhood acute lymphoblastic leukemia with 11q23 rearrangements. Leukemia 2003, 17, 700-706. [CrossRef]

102. Basso, G.; Veltroni, M.; Valsecchi, M.G.; Dworzak, M.N.; Ratei, R.; Silvestri, D.; Benetello, A.; Buldini, B.; Maglia, O.; Masera, G.; et al. Risk of relapse of childhood acute lymphoblastic leukemia is predicted by flow cytometric measurement of residual disease on day 15 bone marrow. J. Clin. Oncol. 2009, 27, 5168-5174. [CrossRef] [PubMed]

103. Schultz, K.R.; Devidas, M.; Bowman, W.P.; Aledo, A.; Slayton, W.B.; Sather, H.; Zheng, H.W.; Davies, S.M.; Gaynon, P.S.; Trigg, M.; et al. Philadelphia chromosome-negative very high-risk acute lymphoblastic leukemia in children and adolescents: Results from Children's Oncology Group Study AALL0031. Leukemia 2014, 28, 964-967. [CrossRef]

104. Hann, I.; on behalf of the UK Medical Research Council's Working Party on Childhood Leukaemia; Vora, A.; Richards, S.; Hill, F.; Gibson, B.; Lilleyman, J.; Kinsey, S.; Mitchell, C.; Eden, O.B. Benefit of intensified treatment for all children with acute lymphoblastic leukaemia: Results from MRC UKALL XI and MRC ALL97 randomised trials. UK Medical Research Council's Working Party on Childhood Leukemia. Leukemia 2000, 14, 356-363. [CrossRef] [PubMed]

105. Mullighan, C.G.; Jeha, S.; Pei, D.; Payne-Turner, D.; Coustan-Smith, E.; Roberts, K.G.; Waanders, E.; Choi, J.K.; Ma, X.; Raimondi, S.C.; et al. Outcome of children with hypodiploid ALL treated with risk-directed therapy based on MRD levels. Blood 2015, 126, 2896-2899. [CrossRef]

106. Moorman, A.V.; Ensor, H.M.; Richards, S.M.; Chilton, L.; Schwab, C.; Kinsey, S.E.; Vora, A.; Mitchell, C.D.; Harrison, C.J. Prognostic effect of chromosomal abnormalities in childhood B-cell precursor acute lymphoblastic leukaemia: Results from the UK Medical Research Council ALL97/99 randomised trial. Lancet Oncol. 2010, 11, 429-438. [CrossRef]

107. Safavi, S.; Paulsson, K. Near-haploid and low-hypodiploid acute lymphoblastic leukemia: Two distinct subtypes with consistently poor prognosis. Blood 2017, 129, 420-423. [CrossRef]

108. Moorman, A.V.; Chilton, L.; Wilkinson, J.; Ensor, H.M.; Bown, N.; Proctor, S.J. A population-based cytogenetic study of adults with acute lymphoblastic leukemia. Blood 2010, 115, 206-214. [CrossRef]

109. Pui, C.-H.; Rebora, P.; Schrappe, M.; Attarbaschi, A.; Baruchel, A.; Basso, G.; Cavé, H.; Elitzur, S.; Koh, K.; Liu, H.-C.; et al. Outcome of Children with Hypodiploid Acute Lymphoblastic Leukemia: A Retrospective Multinational Study. J. Clin. Oncol. 2019, 37, 770-779. [CrossRef] [PubMed]

110. Harrison, C.; Moorman, A.; Broadfield, Z.J.; Cheung, K.L.; Harris, R.L.; Jalali, G.R.; Robinson, H.M.; Barber, K.E.; Richards, S.M.; Mitchell, C.D.; et al. Three distinct subgroups of hypodiploidy in acute lymphoblastic leukaemia. Br. J. Haematol. 2004, 125, 552-559. [CrossRef] [PubMed]

111. McNeer, J.L.; Devidas, M.; Dai, Y.; Carroll, A.J.; Heerema, N.A.; Gastier-Foster, J.M.; Kahwash, S.; Borowitz, M.J.; Wood, B.L.; Larsen, E.; et al. Hematopoietic Stem-Cell Transplantation Does Not Improve the Poor Outcome of Children With Hypodiploid Acute Lymphoblastic Leukemia: A Report From Children's Oncology Group. J. Clin. Oncol. 2019, 37, 780-789. [CrossRef] [PubMed] 
112. Nachman, J.B.; Heerema, N.A.; Sather, H.; Camitta, B.; Forestier, E.; Harrison, C.J.; Dastugue, N.; Schrappe, M.; Pui, C.-H.; Basso, G.; et al. Outcome of treatment in children with hypodiploid acute lymphoblastic leukemia. Blood 2007, 110, 1112-1115. [CrossRef] [PubMed]

113. Schmiegelow, K.; Forestier, E.; Hellebostad, M.; Heyman, M.; Kristinsson, J.; Söderhäll, S.; Taskinen, M. Long-term results of NOPHO ALL-92 and ALL-2000 studies of childhood acute lymphoblastic leukemia. Leukemia 2010, 24, 345-354. [CrossRef] [PubMed]

114. Qian, M.; Cao, X.; Devidas, M.; Yang, W.; Cheng, C.; Dai, Y.; Carroll, A.; Heerema, N.A.; Zhang, H.; Moriyama, T.; et al. TP53 Germline Variations Influence the Predisposition and Prognosis of B-Cell Acute Lymphoblastic Leukemia in Children. J. Clin. Oncol. 2018, 36, 591-599. [CrossRef] [PubMed]

115. Hunger, S.P.; Ohyashiki, K.; Toyama, K.; Cleary, M.L. Hlf, a novel hepatic bZIP protein, shows altered DNA-binding properties following fusion to E2A in $\mathrm{t}(17 ; 19)$ acute lymphoblastic leukemia. Genes Dev. 1992, 6, 1608-1620. [CrossRef] [PubMed]

116. Mouttet, B.; Vinti, L.; Ancliff, P.; Bodmer, N.; Brethon, B.; Cario, G.; Chen-Santel, C.; Elitzur, S.; Hazar, V.; Kunz, J.; et al. Durable remissions in TCF3-HLF positive acute lymphoblastic leukemia with blinatumomab and stem cell transplan-tation. Haematologica 2019, 104, e244-e247. [CrossRef] [PubMed]

117. Fischer, U.; Forster, M.; Rinaldi, A.; Risch, T.; Sungalee, S.; Warnatz, H.-J.; Bornhauser, B.; Gombert, M.; Kratsch, C.; Stütz, A.M.; et al. Genomics and drug profiling of fatal TCF3-HLF-positive acute lymphoblastic leukemia identifies recurrent mutation patterns and therapeutic options. Nat. Genet. 2015, 47, 1020-1029. [CrossRef]

118. Harrison, C.J. Blood Spotlight on iAMP21 acute lymphoblastic leukemia (ALL), a high-risk pediatric disease. Blood 2015, 125, 1383-1386. [CrossRef]

119. Harrison, C.J.; Moorman, A.V.; Schwab, C.; Carroll, A.J.; Raetz, E.A.; Devidas, M.; Strehl, S.; Nebral, K.; Harbott, J.; Teigler-Schlegel, A.; et al. An international study of intrachromosomal amplification of chromosome 21 (iAMP21): Cytogenetic characterization and outcome. Leukemia 2014, 28, 1015-1021. [CrossRef]

120. Heerema, N.A.; Carroll, A.J.; Devidas, M.; Loh, M.L.; Borowitz, M.J.; Gastier-Foster, J.M.; Larsen, E.C.; Mattano, L.A., Jr.; Maloney, K.W.; Willman, C.L.; et al. Intrachromosomal amplification of chromosome 21 is associated with inferior outcomes in children with acute lymphoblastic leukemia treated in contemporary standard-risk children's oncology group studies: A report from the children's oncology group. J. Clin. Oncol. 2013, 31, 3397-3402. [CrossRef]

121. Attarbaschi, A.; Mann, G.; Panzer-Grümayer, R.; Röttgers, S.; Steiner, M.; König, M.; Csinady, E.; Dworzak, M.N.; Seidel, M.G.; Janousek, D.; et al. Minimal residual disease values discriminate between low and high relapse risk in children with B-cell precursor acute lymphoblastic leukemia and an intrachromosomal amplification of chromosome 21: The Austrian and German acute lymphoblastic leukemia Berlin-Frankfurt-Münster (ALL-BFM) trials. J. Clin. Oncol. 2008, 26, 3046-3050. [CrossRef]

122. Moorman, A.V.; Robinson, H.; Schwab, C.; Richards, S.M.; Hancock, J.; Mitchell, C.D.; Goulden, N.; Vora, A.; Harrison, C.J. Risk-directed treatment intensification significantly reduces the risk of relapse among children and adolescents with acute lymphoblastic leukemia and intrachromosomal amplification of chromosome 21: A comparison of the MRC ALL97/99 and UKALL2003 trials. J. Clin. Oncol. 2013, 31, 3389-3396. [CrossRef]

123. Waanders, E.; van der elden, V.H.; van der Schoot, E.; van Leeuwen, F.N.; van Reijmersdal, S.V.; de Haas, V.; Veerman, A.J.; van Kessel, A.G.; Hoogerbrugge, P.M.; Kuiper, R.P.; et al. Integrated use of minimal residual disease classification and IKZF1 alteration status accurately predicts 79\% of relapses in pediatric acute lymphoblastic leukemia. Leukemia 2011, 25, 254-258. [CrossRef]

124. Mullighan, C.G.; Su, X.; Zhang, J.; Radtke, I.; Phillips, L.A.A.; Miller, C.B.; Ma, J.; Liu, W.; Cheng, C.; Schulman, B.A.; et al. Deletion ofIKZF1and prognosis in acute lymphoblastic leukemia. N. Engl. J. Med. 2009, 360, 470-480. [CrossRef] [PubMed]

125. Asai, D.; Imamura, T.; Suenobu, S.; Saito, A.; Hasegawa, D.; Deguchi, T.; Hashii, Y.; Matsumoto, K.; Kawasaki, H.; Hori, H.; et al. IKZF1deletion is associated with a poor outcome in pediatric B-cell precursor acute lymphoblastic leukemia in Japan. Cancer Med. 2013, 2, 412-419. [CrossRef]

126. Palmi, C.; Valsecchi, M.G.; Longinotti, G.; Silvestri, D.; Carrino, V.; Conter, V.; Basso, G.; Biondi, A.; Kronnie, G.T.; Cazzaniga, G. What is the relevance of Ikaros gene deletions as a prognostic marker in pediatric Philadelphia-negative B-cell precursor acute lymphoblastic leukemia? Haematologica 2013, 98, 1226-1231. [CrossRef] [PubMed]

127. Iacobucci, I.; Storlazzi, C.T.; Cilloni, D.; Lonetti, A.; Ottaviani, E.; Soverini, S.; Astolfi, A.; Chiaretti, S.; Vitale, A.; Messa, F.; et al. Identification and molecular characterization of recurrent genomic deletions on 7p12 in the IKZF1 gene in a large cohort of BCR-ABL1-positive acute lymphoblastic leukemia patients: On behalf of Gruppo Italiano Malattie Ematologiche dell'Adulto Acute Leukemia Working Party (GIMEMA AL WP). Blood 2009, 114, 2159-2167. [CrossRef]

128. Lopes, B.A.; Meyer, C.; Barbosa, T.C.; Stadt, U.Z.; Horstmann, M.; Venn, N.C.; Heatley, S.; White, D.L.; Sutton, R.; Pombo-DeOliveira, M.S.; et al. COBL is a novel hotspot for IKZF1 deletions in childhood acute lymphoblastic leukemia. Oncotarget 2016, 7, 53064-53073. [CrossRef] [PubMed]

129. Dörge, P.; Meissner, B.; Zimmermann, M.; Möricke, A.; Schrauder, A.; Bouquin, J.P.; Schewe, D.; Harbott, J.; Teigler-Schlegel, A.; Ratei, R.; et al. IKZF1 deletion is an independent predictor of outcome in pediatric acute lymphoblastic leukemia treated according to the ALL-BFM 2000 protocol. Haematologica 2013, 98, 428-432. [CrossRef] [PubMed]

130. Clappier, E.; Grardel, N.; Bakkus, M.; Rapion, J.; De Moerloose, B.; Kastner, P.; Caye, A.; Vivent, J.; Costa, V.; Ferster, A.; et al. IKZF1 deletion is an independent prognostic marker in childhood B-cell precursor acute lymphoblastic leukemia, and distinguishes patients benefiting from pulses during maintenance therapy: Results of the EORTC Children's Leukemia Group study 58951. Leukemia 2015, 29, 2154-2161. [CrossRef] [PubMed] 
131. Buitenkamp, T.D.; Pieters, R.; Gallimore, N.E.; van der Veer, A.; Meijerink, J.P.; Beverloo, H.B.; Zimmermann, M.; de Haas, V.; Richards, S.M.; Vora, A.J.; et al. Outcome in children with Down's syndrome and acute lymphoblastic leukemia: Role of IKZF1 deletions and CRLF2 aberrations. Leukemia 2012, 26, 2204-2211. [CrossRef] [PubMed]

132. Stanulla, M.; Dagdan, E.; Zaliova, M.; Möricke, A.; Palmi, C.; Cazzaniga, G.; Eckert, C.; Te Kronnie, G.; Bourquin, J.P.; Bornhauser, B.; et al. IKZF1plus Defines a New Minimal Residual Disease-Dependent Very-Poor Prognostic Profile in Pediatric B-Cell Precursor Acute Lymphoblastic Leukemia. J. Clin. Oncol. 2018, 36, 1240-1249. [CrossRef] [PubMed]

133. Yang, Y.-L.; Hung, C.-C.; Chen, J.-S.; Lin, K.-H.; Jou, S.-T.; Hsiao, C.-C.; Sheen, J.-M.; Cheng, C.-N.; Wu, K.-H.; Lin, S.-R.; et al. IKZF1 deletions predict a poor prognosis in children with B-cell progenitor acute lymphoblastic leukemia: A multicenter analysis in Taiwan. Cancer Sci. 2011, 102, 1874-1881. [CrossRef] [PubMed]

134. Kuiper, R.P.; Waanders, E.; Van Der Velden, V.H.J.; Van Reijmersdal, S.V.; Venkatachalam, R.; Scheijen, B.; Sonneveld, E.; Van Dongen, J.J.M.; Veerman, A.J.P.; Van Leeuwen, F.N.; et al. IKZF1 deletions predict relapse in uniformly treated pediatric precursor B-ALL. Leukemia 2010, 24, 1258-1264. [CrossRef] [PubMed]

135. Van Der Veer, A.; Zaliova, M.; Mottadelli, F.; De Lorenzo, P.; Te Kronnie, G.; Harrison, C.J.; Cavé, H.; Trka, J.; Saha, V.; Schrappe, M.; et al. IKZF1 status as a prognostic feature in BCR-ABL1-positive childhood ALL. Blood 2014, 123, 1691-1698. [CrossRef] [PubMed]

136. Van Der Veer, A.; Waanders, E.; Pieters, R.; Willemse, M.; Van Reijmersdal, S.; Russell, L.; Harrison, C.; Evans, W.; Van Der Velden, V.; Hoogerbrugge, P.; et al. Independent prognostic value of BCR-ABL1-like signature and IKZF1 deletion, but not high CRLF2 expression, in children with B-cell precursor ALL. Blood 2013, 122, 2622-2629. [CrossRef]

137. Irving, J.A.E.; Enshaei, A.; Parker, C.A.; Sutton, R.; Kuiper, R.P.; Erhorn, A.; Minto, L.; Venn, N.C.; Law, T.; Yu, J.; et al. Integration of genetic and clinical risk factors improves prognostication in relapsed childhood B-cell precursor acute lymphoblastic leukemia. Blood 2016, 128, 911-922. [CrossRef] [PubMed]

138. Krentz, S.; Hof, J.; Mendioroz, A.; Vaggopoulou, R.; Dörge, P.; Lottaz, C.; Engelmann, J.C.; Groeneveld, T.; Körner, G.; Seeger, K.; et al. Prognostic value of genetic alterations in children with first bone marrow relapse of childhood B-cell precursor acute lymphoblastic leukemia. Leukemia 2012, 27, 295-304. [CrossRef]

139. Churchman, M.L.; Mullighan, C.G. Ikaros: Exploiting and targeting the hematopoietic stem cell niche in B-progenitor acute lym-phoblastic leukemia. Exp. Hematol. 2017, 46, 1-8. [CrossRef] [PubMed]

140. Churchman, M.L.; Low, J.; Qu, C.; Paietta, E.M.; Kasper, L.H.; Chang, Y.; Payne-Turner, D.; Althoff, M.J.; Song, G.; Chen, S.-C.; et al. Efficacy of Retinoids in IKZF1-Mutated BCR-ABL1 Acute Lymphoblastic Leukemia. Cancer Cell 2015, 28, 343-356. [CrossRef] [PubMed]

141. Churchman, M.L.; Qian, M.; Kronnie, G.T.; Zhang, R.; Yang, W.; Zhang, H.; Lana, T.; Tedrick, P.; Baskin, R.; Verbist, K.; et al. Germline Genetic IKZF1 Variation and Predisposition to Childhood Acute Lymphoblastic Leukemia. Cancer Cell 2018, 33, 937-948.e8. [CrossRef]

142. Gianni, F.; Belver, L.; Ferrando, A. The Genetics and Mechanisms of T-Cell Acute Lymphoblastic Leukemia. Cold Spring Harb. Perspect. Med. 2020, 10, a035246. [CrossRef]

143. Ferrando, A.A.; Neuberg, D.S.; Staunton, J.; Loh, M.L.; Huard, C.; Raimondi, S.C.; Behm, F.G.; Pui, C.-H.; Downing, J.R.; Gilliland, D.; et al. Gene expression signatures define novel oncogenic pathways in T cell acute lymphoblastic leukemia. Cancer Cell 2002, 1, 75-87. [CrossRef]

144. Coustan-Smith, E.; Mullighan, C.G.; Onciu, M.; Behm, F.G.; Raimondi, S.C.; Pei, D.; Cheng, C.; Su, X.; Rubnitz, J.E.; Basso, G.; et al. Early T-cell precursor leukaemia: A subtype of very high-risk acute lymphoblastic leukaemia. Lancet Oncol. 2009, 10, 147-156. [CrossRef]

145. Chonghaile, T.N.; Roderick, J.E.; Glenfield, C.; Ryan, J.; Sallan, S.E.; Silverman, L.B.; Loh, M.L.; Hunger, S.P.; Wood, B.; DeAngelo, D.J.; et al. Maturation stage of T-cell acute lymphoblastic leukemia determines BCL-2 versus BCL-XL dependence and sensitivity to ABT-199. Cancer Discov. 2014, 4, 1074-1087. [CrossRef] [PubMed]

146. Jaime-Pérez, J.C.; Santos, J.A.H.-D.L.; Gómez-Almaguer, D. Childhood T-cell acute lymphoblastic leukemia in a single Latin American center: Impact of improved treatment scheme and support therapy on survival. Hematol. Transfus. Cell Ther. 2020, 42, 320-325. [CrossRef] [PubMed]

147. Zhang, H.-H.; Wang, H.-S.; Qian, X.-W.; Fan, C.-Q.; Li, J.; Miao, H.; Zhu, X.-H.; Yu, Y.; Meng, J.-H.; Cao, P.; et al. Genetic variants and clinical significance of pediatric acute lymphoblastic leukemia. Ann. Transl. Med. 2019, 7, 296. [CrossRef] [PubMed]

148. D’Angiò, M.; Valsecchi, M.G.; Testi, A.M.; Conter, V.; Nunes, V.; Parasole, R.; Colombini, A.; Santoro, N.; Varotto, S.; Caniglia, M.; et al. Clinical features and outcome of SIL/TAL1-positive T-cell acute lymphoblastic leukemia in children and adolescents: A 10-year experience of the AIEOP group. Haematologica 2015, 100, e10-e13. [CrossRef]

149. Patrick, K.; Wade, R.; Goulden, N.; Mitchell, C.; Moorman, A.V.; Rowntree, C.; Jenkinson, S.; Hough, R.; Vora, A. Outcome for children and young people with Early T-cell precursor acute lymphoblastic leukaemia treated on a con-temporary protocol, UKALL 2003. Br. J. Haematol. 2014, 166, 421-424. [CrossRef]

150. Schrappe, M.; Valsecchi, M.G.; Bartram, C.R.; Schrauder, A.; Panzer-Grümayer, R.; Möricke, A.; Parasole, R.; Zimmermann, M.; Dworzak, M.; Buldini, B.; et al. Late MRD response determines relapse risk overall and in subsets of childhood T-cell ALL: Results of the AIEOP-BFM-ALL 2000 study. Blood 2011, 118, 2077-2084. [CrossRef]

151. Teachey, D.T.; O'Connor, D. How I treat newly diagnosed T-cell acute lymphoblastic leukemia and T-cell lymphoblastic lymphoma in children. Blood 2020, 135, 159-166. [CrossRef] 
152. Dunsmore, K.P.; Winter, S.S.; Devidas, M.; Wood, B.L.; Esiashvili, N.; Chen, Z.; Eisenberg, N.; Briegel, N.; Hayashi, R.J.; GastierFoster, J.M.; et al. Children's Oncology Group AALL0434: A Phase III Randomized Clinical Trial Testing Nelarabine in Newly Diagnosed T-Cell Acute Lymphoblastic Leukemia. J. Clin. Oncol. 2020, 38, 3282-3293. [CrossRef]

153. Goldberg, J.M.; Silverman, L.B.; Levy, D.E.; Dalton, V.K.; Gelber, R.D.; Lehmann, L.; Cohen, H.J.; Sallan, S.E.; Asselin, B.L. Childhood T-cell acute lymphoblastic leukemia: The Dana-Farber Cancer Institute acute lymphoblastic leukemia consortium experience. J. Clin. Oncol. 2003, 21, 3616-3622. [CrossRef]

154. Winter, S.S.; Dunsmore, K.P.; Devidas, M.; Wood, B.L.; Esiashvili, N.; Chen, Z.; Eisenberg, N.; Briegel, N.; Hayashi, R.J.; GastierFoster, J.M.; et al. Improved Survival for Children and Young Adults With T-Lineage Acute Lymphoblastic Leukemia: Results From the Children's Oncology Group AALL0434 Methotrexate Randomization. J. Clin. Oncol. 2018, 36, 2926-2934. [CrossRef] [PubMed]

155. Steinherz, P.G.; Gaynon, P.S.; Breneman, J.C.; Cherlow, J.M.; Grossman, N.J.; Kersey, J.H.; Johnstone, H.S.; Sather, H.N.; Trigg, M.E.; Uckun, F.M.; et al. Treatment of patients with acute lymphoblastic leukemia with bulky extramedullary disease and T-cell phenotype or other poor prognostic features. Cancer 1998, 82, 600-612. [CrossRef]

156. Reismüller, B.; Attarbaschi, A.; Peters, C.; Dworzak, M.N.; Pötschger, U.; Urban, C.; Fink, F.-M.; Meister, B.; Schmitt, K.; Dieckmann, K.; et al. Long-term outcome of initially homogenously treated and relapsed childhood acute lymphoblastic leukaemia in Austria-A population-based report of the Austrian Berlin-Frankfurt-Münster (BFM) Study Group. Br. J. Haematol. 2009, 144, 559-570. [CrossRef] [PubMed]

157. Raetz, E.A.; Teachey, D.T. T-cell acute lymphoblastic leukemia. Hematology 2016, 2016, 580-588. [CrossRef] [PubMed]

158. Gocho, Y.; Liu, J.; Hu, J.; Yang, W.; Dharia, N.V.; Zhang, J.; Shi, H.; Du, G.; John, A.; Lin, T.-N.; et al. Network-based systems pharmacology reveals heterogeneity in LCK and BCL2 signaling and therapeutic sensitivity of T-cell acute lymphoblastic leukemia. Nat. Cancer 2021, 2, 284-299. [CrossRef] [PubMed] 